\title{
Análise das relações das variáveis logísticas com a organização e estratégia das empresas de construção
}

Analysis of the relations of the logistic variables with the organisation and strategy of construction companies

\section{Sofia Gauginski Maia \\ Alfredo larozinski Neto \\ Sergio Eduardo Gouvea da Costa Cezar Augusto Romano}

\section{Resumo}

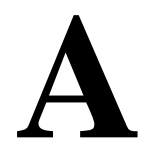

necessidade de construir de forma eficiente, com prazos curtos e com menos custos, é uma das características para as construtoras sobreviverem num mercado cada vez mais competitivo. Devido à importância da logística na organização, o presente artigo tem como objetivo entender como os mecanismos das variáveis relacionadas à logística afetam o funcionamento de uma organização e impactam a estratégia das empresas de construção. Para tanto foi desenvolvido um estudo aplicado, descritivo, de natureza quantitativa e tempo transversal. Como procedimento principal foi escolhido o método Survey com análise de correlação entre as variáveis com base no Método da Matriz de Impacto Cruzado - Multiplicação Aplicada a uma Classificação (Micmac). Os resultados mostraram que as organizações têm predisposição a contratos de parcerias, com busca de informações junto aos fornecedores e frequentes ações conjuntas para a redução dos prazos de execução. Também procuram ter uma relação mais próxima com os clientes. Os resultados da pesquisa indicam ainda que a logística tem pouca influência na dinâmica do sistema e que as variáveis estratégicas se destacam como um papel importante no processo de desenvolvimento da empresa.

Palavras-chave: Logística na construção civil. Suprimentos. Gestão de empresas. Características organizacionais. Estratégia.

${ }^{1}$ Sofia Gauginski Maia Universidade Tecnológica Federal do Curitiba - PR - Brasil https:// orcid. org/ 0000-0002-2847-6065

${ }^{2}$ Alfredo larozinski Neto 2 Universidade Tecnológica Federal do Paraná Curitiba - PR - Brasil

\footnotetext{
${ }^{3}$ Sergio Edurado Gouvea da Costa

${ }^{3}$ Pontifícia Universidade Católica do

Paraná

Curitiba - PR - Brasil
}

${ }^{4}$ Cezar Augusto Romano ${ }^{4}$ Universidade Tecnológica Federal do Curitiba - PR - Brasil

Recebido em 13/03/18 Aceito em 04/04/19

\section{Abstract}

Building efficiently with short deadlines and lower costs is an objective that builders strive to achieve in order to survive in an increasingly competitive market. Due to the importance of logistics in any organisation, this article aims to understand how the mechanisms by which variables related to logistics affect the functioning of an organisation and influence the strategy of construction companies. For this purpose, an applied, descriptive study of qualitative and transverse time was developed. The main procedure chosen for the study was the Survey method with a correlation analysis between variables based on Micmac. The results showed that organisations have a predisposition to establish partnership contracts, seeking information from suppliers and frequent joint actions to reduce execution deadlines. They also seek to have a closer relationship with clients. The results of the research project also indicate that logistics has little influence on the dynamics of the system and that the strategic variables stand out as an important role in the process of development of the company.

Keywords: Logistics in construction. Supplies. Business management. Organisational characteristics. Strategy. 


\section{Introdução}

Nos últimos anos, a construção civil privilegiou a área técnico-estrutural, enquanto a área de suprimentos foi pouco explorada. Com a necessidade de fazer obras com prazos curtos e menos desperdícios, a preocupação com o gerenciamento do fluxo de suprimentos passou a ser um ponto-chave para as construtoras (BARBOSA; MUNIZ; SANTOS, 2007).

Nesse contexto, almejando melhorar os ganhos da organização na direção de maior competividade, o ponto crucial do processo logístico está em visualizar o potencial de um sistema de forma integrada, e, para alcançar esse objetivo, deve-se ter o conhecimento de quais são as atividades logísticas existentes e procurar relacioná-las à empresa estudada (BOWERSOX; CLOSS; COOPER, 2007).

Verma e Seth (2011), ao estudar os conceitos da competividade da cadeia de suprimentos, destacam a importância desse tema nos últimos anos devido aos desafios enfrentados pelas organizações no ambiente global, o que gera a necessidade de parcerias de cooperação e colaboração, quando flexibilidade, agilidade e eficiência têm prioridade competitiva.

Papadopoulos et al. (2016) relatam a falta de estudos acadêmicos mais aprofundados na melhoria da cadeia de suprimentos na construção civil e também evidenciam a demonstração de interesse de grandes empresas de construção em melhorar a produtividade com o intuito de atender às demandas de entrega de projetos de alta qualidade a preços competitivos.

Dessa forma, devido à importância da logística no processo administrativo e a sua complexidade, e considerando o impacto que esse cenário tem nas construtoras, é válido entender as relações da logística com as outras atividades administrativas da empresa para o bom funcionamento do todo. Nesse contexto, este estudo tem como objetivo analisar as relações entre os aspectos logísticos, as características da organização e as estratégias das empresas na construção civil.

Os trabalhos relacionados à logística do setor da construção geralmente focam um aspecto da organização: ou a estratégia (PALANDENG, 2018), ou o impacto no desempenho/ competitividade (ARORA; ARORA; SIVAKUMAR, 2016), ou as características organizacionais (LIN et al., 2005). O presente artigo visa a uma abordagem sistêmica do estudo da logística em relação à organização empresarial. A contribuição está no fato de se estudar a logística levando em conta as relações simultâneas dos principais grupos de variáveis que participam da dinâmica organizacional e estratégica de uma empresa do setor da construção. A logística é estudada no contexto global da organização.

\section{Estudo bibliográfico}

O estudo bibliográfico foi desenvolvido com dois focos principais: o referencial teórico, que apresenta brevemente os conceitos e definições que são as bases teóricas de sustentação do trabalho; e a revisão da literatura, que apresenta um levantamento daquilo que já foi publicado em pesquisas relacionadas ao tema deste artigo.

\section{Referencial teórico}

Para dar sustentação ao modelo de organização utilizado neste trabalho foram necessárias bases teóricas e conceituais para a definição de cinco grupos de variáveis: estrutura organizacional, estratégia, ambiente concorrencial, desempenho e logística.

A estrutura organizacional pode ser definida como o resultado de um processo através do qual a autoridade é distribuída, as atividades são especificadas e um sistema de comunicação é delineado, o que permite que as pessoas realizem as atividades e exerçam a autoridade que lhes compete para atingir os objetivos organizacionais (VASCONCELLOS; HEMSLEY, 2002).

Segundo Stoner e Freeman (1999), o modelo organizacional é definido por cinco elementos: a especificação de tarefas, que se refere à divisão do trabalho e ao nível de departamentalização; a padronização das tarefas; a coordenação das atividades, composta dos procedimentos realizados de forma a integrar as funções das subunidades da organização; a centralização e a descentralização das decisões; e o tamanho das unidades de trabalho.

A relação entre estrutura organizacional e estratégia é explorada nos trabalhos de Mintzberg (1983). Ele mostra que cada configuração organizacional é fruto de uma estratégia adotada pela empresa. Mintzberg (1983) apresenta como principais características organizacionais afetadas pela estratégia a especialização do trabalho, a formalização do comportamento, o treinamento, a departamentalização, os sistemas de planejamento e controle, os meios de ligação e a descentralização vertical e horizontal. As estruturas organizacionais, assim como a divisão do trabalho e as formas de coordenação, formalização e descentralização, variam de acordo com alguns fatores situacionais, como ambiente, tamanho da organização, 
tecnologia e processos produtivos utilizados (MINTZBERG, 2003).

Os modelos de estratégia empresarial foram descritos por diversos pesquisadores, como Skinner (1985), Pfeffer e Salancik (1978) e Barney (1991). Entretanto, o modelo mais conhecido e utilizado é, sem dúvida, o Modelo da Estratégia Competitiva de Michael Porter (PORTER, 1993). Esse modelo está consolidado na literatura e nas práticas das organizações empresariais (ANTONIALLI et al., 2017).

O modelo de Porter está baseado no valor que se pode agregar ao conjunto de atividades de uma organização a partir de ações que podem aumentar a vantagem competitiva da organização em relação aos concorrentes em dado mercado. A organização pode optar por duas estratégias genéricas: custo ou diferenciação. Após a análise do ambiente, uma das duas estratégias deve ser adotada, e ações na cadeia de valores da organização devem ser implementadas para sustentar a estratégia.

Para Porter (1993), o ambiente competitivo próximo é regulado por cinco forças, a saber: o poder de negociação dos fornecedores; o poder de negociação dos compradores; a entrada de novos concorrentes; a rivalidade entre os concorrentes existentes; e a ameaça de substitutos. Cada uma dessas cinco forças é associada a um conjunto de variáveis que as definem. Esse modelo é bastante abrangente para representar o ambiente concorrencial de uma organização empresarial.

Slack, Chambers e Johnston (2009) incorporam o modelo de Porter em sua proposta para a gestão da produção da mesma forma que fazem uma síntese do conjunto de indicadores de desempenho passíveis de ser utilizados para avaliar o efeito das ações estratégicas e operacionais pelas organizações empresariais. Esses indicadores foram divididos em cinco grupos: custo, prazo, flexibilidade, qualidade e aspectos socioambientais.

A base teórica e conceitual mais "clássica” em relação à logística pode ser encontrada nos trabalhos de Ballou (2011, 2009, 2007), os quais não apresentam os avanços mais recentes na área, mas comtemplam as bases conceituais necessárias à definição das principais variáveis que definem a logística numa organização empresarial. Segundo Ballou (2011), a logística é um plano administrativo e facilitador do fluxo de produtos, que gera aumento da rentabilidade dos serviços mediante o controle das atividades, da organização e do planejamento. O autor ainda descreve a importância da logística e a necessidade do planejamento como meio de diminuir os riscos e aumentar o sucesso das organizações no mercado competitivo.
Na literatura, a logística no setor da construção civil é tratada como pouco desenvolvida em relação aos outros setores da economia (REZENDE; JESUS; MOURA, 2013). Segundo Martinho, Jesus e Campos Neto (2015), a logística favorece um bom gerenciamento e um alto índice de produtividade nas obras, portanto a maior utilização desses conceitos no setor resultaria em melhores lucros, na redução de custos e no efetivo controle de qualidade.

\section{Revisão da literatura sobre os principais estudos sobre logística na construção civil}

A busca neste trabalho por estudos referentes à logística na construção civil encontrados na base de dados Scopus resultou em publicações a partir do ano de 1998. O artigo de Agapiou et al. (1998), um dos pioneiros no estudo do assunto, afirma a relevância da logística no setor de construção e descreve um modelo logístico para gerenciar o fluxo de materiais de fornecedores em um projeto dinamarquês de construção de casas.

Akintoye, McIntosh e Fitzgerald (2000) relatam em pesquisa sobre a colaboração e a gestão da cadeia de suprimentos da indústria de construção do Reino Unido, feita a partir de um questionário (Survey), que o gerenciamento da cadeia de suprimentos da construção ainda estava na fase inicial de desenvolvimento, apesar da consciência da importância refletida e caracterizada na crescente formação de um número significativo de parcerias entre os empreiteiros, fornecedores e clientes. Os relatórios de Latham (1994) e Egan (1998) destacam a utilidade da gestão da cadeia de suprimentos para a indústria da construção civil ao procurar práticas na indústria do Reino Unido com o intuito de aumentar sua eficiência. Os resultados identificaram como fundamentos o planejamento da produção e a função de compras para a aplicação do gerenciamento da cadeia de suprimentos na construção e citaram como obstáculos ao sucesso os seguintes pontos: a cultura no local de trabalho, falta de compromisso com a alta administração, estruturas de apoio inadequadas e falta de conhecimento do gerenciamento da cadeia de suprimentos. Também indicaram o treinamento e a educação em todos os níveis da empresa para a superação dessas barreiras.

Saad, Jones e James (2002) avaliam os avanços da adoção dos relacionamentos de gerenciamento da cadeia de suprimentos na construção e sugerem que seus profissionais precisam melhorar a compreensão conceitual e as abordagens novas e mais sistemáticas, com vistas à implementação bem-sucedida desse tipo de inovação. 
Os autores Love et al. (2002) apresentam as alianças de aprendizagem cooperativa como forma de se obter uma visão compartilhada do aprendizado mútuo e, dessa forma, melhorar a eficácia das operações comerciais da construção, o que pode resultar na satisfação do cliente interno e externo. Ainda sugerem que as organizações procurem fazer as alianças de longo prazo para ganhar vantagem competitiva em relação a seus concorrentes através da implementação das relações estratégicas com foco no cliente/fornecedor. Vidalakis, Tookey e Sommerville (2011), ao estudar os processos logísticos dentro da indústria da construção, demonstram consideráveis benefícios financeiros (redução de custos, maiores lucros e melhor valor para os clientes) sobre o desempenho da cadeia de suprimentos, apesar da natureza fragmentada e do caráter temporário das organizações.

O relatório de pesquisa de Papadopoulos et al. (2016) fornece um conjunto de proposições para melhorar e alcançar vantagens competitivas através do gerenciamento da cadeia de suprimentos da construção com uma abordagem promissora de integração entre os fornecedores, empreiteiros e clientes com base na colaboração, no compartilhamento de informações e na confiança.

Seppänen e Peltokorpi (2016) concluem em seus estudos sobre a literatura da logística na construção que, apesar da importância do tema, a maioria dos estudos foca em parte do problema e oferece soluções parciais. Também sugerem futuros estudos sobre o impacto da logística no desempenho do sistema de produção, com uma abordagem mais sistemática, para ajudar na compreensão e obter ferramentas de decisões, logísticas considerando todas as variáveis impactadas.

\section{Método}

Esta pesquisa pode ser classificada como aplicada, descritiva, de natureza quantitativa e de abordagem transversal. A metodologia utilizada foi o Survey com a combinação da correlação e utilização do método Multiplicação Matricial Aplicada a uma Classificação (Micmac) para a análise das variáveis estudadas. O desenvolvimento desse método e os processos de análise dos dados são representados na Figura 1 e descritos a seguir.

\section{Pesquisa Survey}

O método Survey deve ser planejado, e sua aplicação associada aos objetivos de pesquisa. A aplicação dessa metodologia é sugerida quando o investigador pretende saber o que, por que, como e/ou quanto se dá determinada situação (FREITAS et al., 2000). O Survey visa à obtenção de dados primários sobre características, ações ou opiniões de determinado grupo de pessoas, indicado como representante de uma população-alvo, por meio de um instrumento de pesquisa predefinido, normalmente um questionário (HAIR JUNIOR et al., 2005).

O método Survey inicia-se após o estabelecimento do referencial teórico. Essas ações colaboram na definição do planejamento (necessidades de informação, identificação das variáveis, definição da população-alvo e amostra, seleção do método para coleta de dados, desenvolvimento do instrumento de coleta e mensuração de dados), e após a realização do teste piloto é aplicada a coleta dos dados (aplicação do questionário, compilação dos dados, avaliação da qualidade de mensuração) e feita a análise deles.

O instrumento de coleta de dados utilizado foi o questionário, preenchido de forma presencial nos anos de 2016 e 2017 por profissionais da área da construção civil. A amostra utilizada é constituída por 73 construtoras com tempos de atividade diversos, sendo a mais antiga fundada em 1895, e a mais nova, em 2017. Da amostra, 33 empresas têm o tipo de administração profissional, 30 familiar, 7 misto e 3 outros tipos. Considerando o critério de classificação do porte das empresas do Instituto Brasileiro de Geografia e Estatística (IBGE) para o segmento da indústria por número de empregados, temos na amostra 26\% empresas micro (até 19), $32 \%$ de porte pequeno (entre 20 e 99 ), $22 \%$ de porte médio (entre 100 e 499) e $20 \%$ de porte grande (acima de 499 funcionários).

O questionário é estruturado em seis partes: perfil da organização, relação com o cliente/fornecedor, características da organização, estratégia e funcionamento, desempenho e características do ambiente concorrencial.

A parte relacionada ao perfil da organização é constituída por questões discursivas e de múltipla escolha, que abrangem a identificação do perfil organizacional como nome da empresa, ano de fundação, número de funcionários, tipo de constituição, administração, área aproximada de construção anual, tipos de certificação, ramo de atuação e quantidade de empreendimentos. Identifica o perfil do entrevistado, como seu cargo, tempo de empresa e curso de formação.

As outras cinco partes estão divididas por questões fechadas, e a mensuração quantitativa característica se dá através da adoção de uma escala de diferencial semântico. De acordo com Aguiar, Correia e Campos (2011), escalas de diferencial semântico são aquelas em que cada item avaliado é polarizado em dois adjetivos (ou frases descritivas) opostos e 
contrários. A escala adotada neste estudo, exemplificada no Quadro 1, é composta de sete graus, postos entre dois adjetivos ou frases descritivas antônimas, em que o respondente deve escolher o grau que melhor representa sua opinião. $\mathrm{O}$ valor 0 representa o ponto neutro em relação aos dois adjetivos antagônicos. É importante destacar que, em função da forma de mensuração, o emprego de escalas acrescenta um caráter subjetivo às análises (SAMARTINI, 2006). Portanto, os resultados finais obtidos devem ser analisados como tendências, e não como valores absolutos.

O Quadro 2 apresenta as variáveis referentes às características do ambiente concorrencial e tem como objetivo compreender os fatores relacionados às cinco forças de Porter (2004): rivalidade entre os concorrentes, poder de barganha dos clientes, poder de barganha dos fornecedores, ameaça de novos entrantes e ameaça de produtos substitutos.

No Quadro 3 são apresentadas as variáveis das características da organização que refletem sobre a estrutura, a forma de gestão, a formação de pessoal e as relações humanas da empresa. Essas variáveis foram definidas com base nos trabalhos de Vasconcellos e Hemsley (2002) e de Mintzberg (1983, 2003).

\section{Figura 1 - Estratégia da pesquisa}

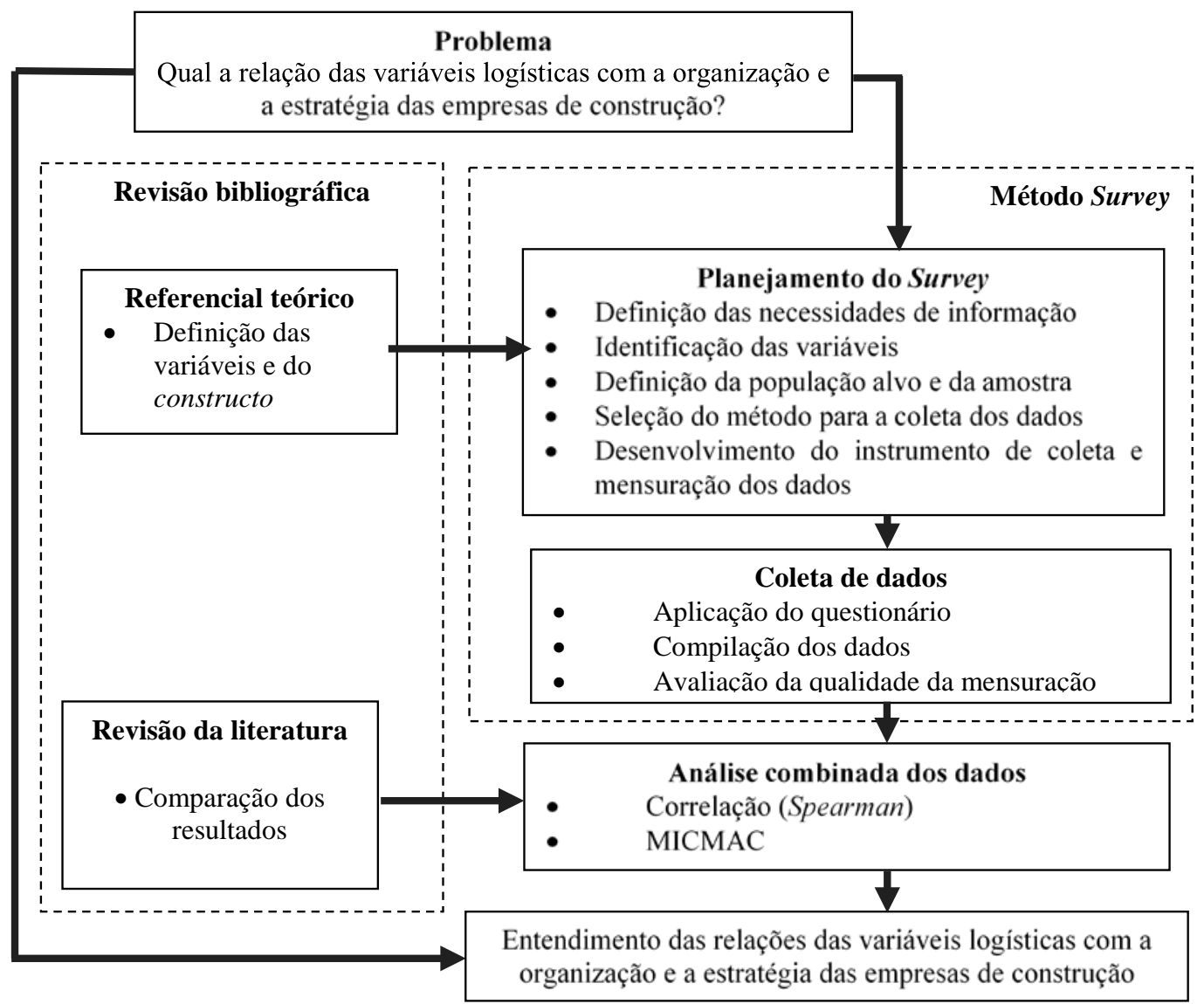

Quadro 1 - Escala de diferencial semântico

\begin{tabular}{|l|l|c|c|c|c|c|c|c|c|l|}
\hline L75 & $\begin{array}{l}\text { As ações conjuntas para redução dos } \\
\text { prazos de execução da obra }\end{array}$ & $\begin{array}{c}\text { nunca } \\
\text { ocorrem }\end{array}$ & 3 & 2 & 1 & 0 & 1 & 2 & 3 & $\begin{array}{l}\text { ocorrem } \\
\text { permanentemente }\end{array}$ \\
\hline L76 & $\begin{array}{l}\text { As mudanças na produção devido às } \\
\text { solicitações/especificações dos clientes }\end{array}$ & $\begin{array}{c}\text { são } \\
\text { frequentes }\end{array}$ & 3 & 2 & 1 & 0 & 1 & 2 & 3 & nunca ocorrem \\
\hline L77 & $\begin{array}{l}\text { A comunicação de alterações de } \\
\text { projeto/especificações aos clientes }\end{array}$ & $\begin{array}{c}\text { são } \\
\text { frequentes }\end{array}$ & 3 & 2 & 1 & 0 & 1 & 2 & 3 & nunca ocorrem \\
\hline
\end{tabular}


Quadro 2 - Características do ambiente concorrencial

\begin{tabular}{|c|c|c|c|}
\hline Legenda & Características do ambiente concorrencial & Extremo inferior & Extremo superior \\
\hline A1 & $\begin{array}{l}\text { As matérias-primas principais podem ser adquiridas } \\
\text { em }\end{array}$ & $\begin{array}{l}\text { um único } \\
\text { fornecedor }\end{array}$ & $\begin{array}{l}\text { muitos } \\
\text { fornecedores }\end{array}$ \\
\hline A2 & O custo/dificuldade de mudança de fornecedores é & inexistente & muito alto \\
\hline A3 & $\begin{array}{l}\text { Produtos substitutos para as matérias-primas } \\
\text { principais }\end{array}$ & não existem & existem para todas \\
\hline A4 & $\begin{array}{l}\text { O impacto da matéria-prima nos custos do } \\
\text { empreendimento é }\end{array}$ & pequeno & grande \\
\hline A5 & $\begin{array}{l}\text { O impacto da matéria-prima nas características do } \\
\text { empreendimento (qualidade, desempenho, etc.) é }\end{array}$ & pequeno & grande \\
\hline A6 & Os fornecedores são & nacionais & mundiais \\
\hline A7 & $\begin{array}{l}\text { A variação dos preços das matérias-primas entre os } \\
\text { fornecedores é }\end{array}$ & pequena & muito grande \\
\hline A8 & $\begin{array}{l}\text { A variação da qualidade das matérias-primas entre os } \\
\text { fornecedores é }\end{array}$ & pequena & muito grande \\
\hline A9 & A quantidade atual de clientes é & pequena & muito grande \\
\hline A10 & Os clientes são & regionais & $\begin{array}{l}\text { de outros } \\
\text { estados/países }\end{array}$ \\
\hline A11 & $\begin{array}{l}\text { A taxa de retorno dos clientes para novas negociações } \\
\text { é }\end{array}$ & pequena & grande \\
\hline A12 & $\begin{array}{l}\text { Para os seus clientes, o custo para deixar de comprar } \\
\text { com a sua empresa e passar a comprar com o seu } \\
\text { concorrente é }\end{array}$ & inexistente & muito alto \\
\hline A13 & $\begin{array}{l}\text { Quanto a tecnologias construtivas diferenciadas (ex.: } \\
\text { steel frame, dry wall, fibras sintéticas, novos sistemas } \\
\text { construtivos, etc.), a empresa }\end{array}$ & não utiliza & utiliza várias \\
\hline A14 & A venda é feita de forma & direta & totalmente indireta \\
\hline A15 & $\begin{array}{l}\text { O nível de diferenciação dos empreendimentos no } \\
\text { setor é }\end{array}$ & \begin{tabular}{|l|l|}
$\begin{array}{l}\text { inexistente } \\
\text { (padronizado) }\end{array}$ \\
\end{tabular} & $\begin{array}{l}\text { altamente } \\
\text { personalizado } \\
\end{array}$ \\
\hline A16 & $\begin{array}{l}\text { O nível de investimento em relação ao custo dos } \\
\text { empreendimentos é }\end{array}$ & muito baixo & muito alto \\
\hline A17 & A tecnologia de execução dos empreendimentos é de & fácil domínio & difícil domínio \\
\hline A18 & A sua "marca” para os seus clientes & não é importante & é muito importante \\
\hline A19 & O nível de competição entre as empresas do setor é & inexistente & muito alto \\
\hline A20 & Os concorrentes da empresa são de porte & pequeno & grande \\
\hline A21 & $\begin{array}{l}\text { A taxa de crescimento do mercado onde a empresa } \\
\text { atua é }\end{array}$ & decrescente & $\begin{array}{l}\text { cresce acima } 20 \% \\
\text { aa }\end{array}$ \\
\hline A22 & A quantidade de empresas concorrentes diretas é & inexistente & muito grande \\
\hline A23 & As vendas da empresa são & bem distribuídas & $\begin{array}{l}\text { muito } \\
\text { concentradas }\end{array}$ \\
\hline A24 & O acesso ao mercado é & muito fácil & muito difícil \\
\hline A25 & O mercado no qual a empresa atua é & não segmentado & muito segmentado \\
\hline A26 & A participação da empresa no mercado em que atua é & muito pequena & muito grande \\
\hline A27 & O mercado em que a empresa atua é & previsível & imprevisível \\
\hline A28 & $\begin{array}{l}\text { A disponibilidade de informações referentes ao } \\
\text { mercado em que a empresa atua é }\end{array}$ & pouca & muito grande \\
\hline
\end{tabular}


Quadro 3 - Características da organização

\begin{tabular}{|c|c|c|c|}
\hline Legenda & Características da organização & Extremo inferior & Extremo superior \\
\hline C29 & $\begin{array}{l}\text { Nível de centralização da estrutura organizacional da } \\
\text { empresa }\end{array}$ & Centralizada & Descentralizada \\
\hline C30 & Grau de hierarquização da empresa & Sem hierarquia & $\begin{array}{l}\text { Muito } \\
\text { hierarquizada }\end{array}$ \\
\hline C31 & Estilo de gestão da empresa & Autocrática & Democrática \\
\hline $\mathrm{C} 32$ & Nível de integração entre os processos de negócio & Baixo & Alto \\
\hline C33 & Nível de departamentalização da empresa & Sem divisão & $\begin{array}{l}\text { Muitos } \\
\text { departamentos }\end{array}$ \\
\hline C34 & $\begin{array}{l}\text { Nível de formalização dos cargos e funções da } \\
\text { empresa }\end{array}$ & Sem formalização & $\begin{array}{l}\text { Totalmente } \\
\text { formalizado }\end{array}$ \\
\hline C35 & $\begin{array}{l}\text { Nível de formalização das atividades e processos } \\
\text { envolvidos na execução das atividades }\end{array}$ & Sem formalização & $\begin{array}{l}\text { Totalmente } \\
\text { formalizado }\end{array}$ \\
\hline C36 & Nível de autonomia dos funcionários & Sem autonomia & Autonomia total \\
\hline C37 & Nível de polivalência dos funcionários & $\begin{array}{l}\text { Realiza uma única } \\
\text { atividade }\end{array}$ & $\begin{array}{l}\text { Realiza múltiplas } \\
\text { atividades }\end{array}$ \\
\hline C38 & Nível de formação dos funcionários & Sem formação & $\begin{array}{l}\text { Maioria com nível } \\
\text { superior e pós- } \\
\text { graduação }\end{array}$ \\
\hline C39 & Quantidade de horas de treinamento/funcionários/ano & Sem treinamento & $\begin{array}{l}\text { Média superior a } \\
12 \text { dias/ano }\end{array}$ \\
\hline $\mathrm{C} 40$ & $\begin{array}{l}\text { Nível de controle exercido sobre as atividades e } \\
\text { funcionários }\end{array}$ & $\begin{array}{l}\text { Sem nenhum } \\
\text { controle }\end{array}$ & Controle intensivo \\
\hline C41 & $\begin{array}{l}\text { Nível de interação (troca de informações formais e } \\
\text { informais) entre os funcionários ou setores }\end{array}$ & $\begin{array}{l}\text { Sem troca de } \\
\text { informações }\end{array}$ & $\begin{array}{l}\text { Intensa troca de } \\
\text { informações }\end{array}$ \\
\hline C42 & $\begin{array}{l}\text { As relações entre funcionários ocorrem com mais } \\
\text { frequência de maneira }\end{array}$ & Formal & Informal \\
\hline C43 & $\begin{array}{l}\text { Nível de cooperação dos funcionários em suas } \\
\text { atividades }\end{array}$ & Sem cooperação & Cooperação total \\
\hline
\end{tabular}

As variáveis referentes à estratégia e ao funcionamento da empresa foram divididas em dois grupos: diferenciação e custo (Quadro 4). Elas estão baseadas no modelo de estratégia de Porter (1993, 2004).

No Quadro 5 são apresentadas as variáveis de desempenho divididas conforme os critérios de desempenho de Slack (2002): qualidade, velocidade, confiabilidade, flexibilidade e custo.

O Quadro 6 apresenta as variáveis referentes à relação com o cliente/fornecedor e abrange as questões sobre a logística em fatores estruturados por custo, qualidade e prazo.

\section{Método da matriz de impacto cruzado}

Os sistemas complexos são caracterizados por uma quantidade significativa de elementos, e muitas vezes esse montante ultrapassa nossa capacidade de análise. Assim, o estudo das inter-relações é um facilitador do conhecimento dos mecanismos de funcionamento de sistemas complexos. A consideração das inter-relações permite perceber todo o sistema e as conexões entre suas partes. Assim, podem-se distinguir as partes constituintes sem perder o sentido do todo.

Para analisar as inter-relações entre variáveis que definem um sistema, pode-se usar um método frequentemente empregado na análise econômica (GODET, 1991; HATEM, 1993): o método da Matriz de Impacto Cruzado - Multiplicação Aplicada a uma Classificação (Micmac). Esse método é caracterizado por sua multidisciplinaridade e seu aspecto matemático. Ele permite estudar as relações entre variáveis de um sistema e mostrar variáveis essenciais.

O Micmac é uma forma de análise estrutural que permite a estruturação coletiva de ideias, a qual possibilita descrever um sistema com a ajuda de uma matriz que conecta todos os seus componentes (variáveis). Ao estudar essas relações, o método tem como objetivo identificar as variáveis mais influente e mais dependentes, além de oferecer a possibilidade de revelar as variáveis essenciais à evolução do sistema. 
Quadro 4 - Estratégia e funcionamento

\begin{tabular}{|c|c|c|c|}
\hline$\overline{\text { Legenda }}$ & Estratégia e Funcionamento & Extremo inferior & Extremo superior \\
\hline E44 & $\begin{array}{l}\text { Posição da empresa em relação à redução de custos } \\
\text { nas suas atividades/processos }\end{array}$ & Sem preocupação & Muito preocupada \\
\hline E45 & $\begin{array}{l}\text { Preocupação com a implantação de inovações em } \\
\text { seus empreendimentos, produtos ou serviços }\end{array}$ & Sem preocupação & Muito preocupada \\
\hline E46 & $\begin{array}{l}\text { Alinhamento das características dos } \\
\text { empreendimentos, produtos ou serviços com a } \\
\text { estratégia adotada pela empresa }\end{array}$ & Sem alinhamento & Bem alinhada \\
\hline E47 & $\begin{array}{l}\text { Nível de conhecimento dos funcionários em relação } \\
\text { às estratégias de gestão adotadas pela empresa }\end{array}$ & Baixo & Alto \\
\hline E48 & $\begin{array}{l}\text { Nível de preocupação da empresa em relação à } \\
\text { adoção de melhorias nos processos gerenciais }\end{array}$ & Sem preocupação & Muito preocupada \\
\hline E49 & $\begin{array}{l}\text { Nível de preocupação da empresa em relação à } \\
\text { prevenção de problemas na execução de seus } \\
\text { empreendimentos ou serviços }\end{array}$ & Nenhuma & Muito preocupada \\
\hline E50 & $\begin{array}{l}\text { Nível de investimentos em tecnologias e } \\
\text { equipamentos realizado nos últimos três anos }\end{array}$ & Nenhum & Muito elevado \\
\hline E51 & $\begin{array}{l}\text { Avaliação das habilidades necessárias aos } \\
\text { funcionários para a execução de suas atividades }\end{array}$ & Sem avaliação & Continuamente \\
\hline E52 & $\begin{array}{l}\text { Instalações e equipamentos existentes em relação às } \\
\text { atividades executadas }\end{array}$ & Inadequados & Adequados \\
\hline E53 & $\begin{array}{l}\text { Preocupação com a oferta de novos produtos e } \\
\text { serviços }\end{array}$ & Nenhuma & Muito preocupada \\
\hline E54 & Preocupação com a aquisição de novas tecnologias & Nenhuma & Muito preocupada \\
\hline E55 & $\begin{array}{l}\text { Preocupação com sistemas de gestão e controle das } \\
\text { atividades }\end{array}$ & Nenhuma & Muito preocupada \\
\hline E56 & $\begin{array}{l}\text { Nível de conhecimento exigidos dos funcionários } \\
\text { sobre técnicas utilizadas no desenvolvimento das } \\
\text { atividades }\end{array}$ & Baixo & Muito alto \\
\hline E57 & $\begin{array}{l}\text { Possui procedimentos gerenciais definidos para } \\
\text { orientar os funcionários em suas atividades }\end{array}$ & Nenhuma & $\begin{array}{l}\text { Todos seguem o } \\
\text { mesmo } \\
\text { procedimento }\end{array}$ \\
\hline E58 & $\begin{array}{l}\text { Preocupação com a verificação (check-list) dos } \\
\text { processos gerenciais relacionadas ao desenvolvimento } \\
\text { das atividades }\end{array}$ & Sem preocupação & Muito preocupada \\
\hline E59 & $\begin{array}{l}\text { Controla das informações sobre as atividades } \\
\text { (orçamento, medições, compras, pagamentos, } \\
\text { contratos, etc.) }\end{array}$ & Sem controle & Muito controle \\
\hline E60 & $\begin{array}{l}\text { No caso de terceirização de processos, a empresa } \\
\text { controla para que os empreendimentos entregues } \\
\text { sigam a padronização da empresa }\end{array}$ & Sem controle & Muito controle \\
\hline E61 & $\begin{array}{l}\text { Nível de diferenciação dos serviços da empresa em } \\
\text { relação a outras empresas do setor }\end{array}$ & $\begin{array}{l}\text { Sem nenhuma } \\
\text { diferenciação }\end{array}$ & $\begin{array}{l}\text { Altamente } \\
\text { diferenciados }\end{array}$ \\
\hline
\end{tabular}


Quadro 5 - Desempenho

\begin{tabular}{|c|l|l|l|}
\hline Legenda & \multicolumn{1}{|c|}{ Desempenho } & Extremo inferior & Extremo superior \\
\hline D62 & $\begin{array}{l}\text { Atendimento dos prazos estipulados para } \\
\text { execução/entrega }\end{array}$ & $\begin{array}{l}\text { Atraso } \\
\text { data prevista }\end{array}$ \\
\hline D63 & Qualidade do produto/serviço entregue ao cliente & $\begin{array}{l}\text { Abaixo do } \\
\text { esperado }\end{array}$ & $\begin{array}{l}\text { Superior ao } \\
\text { esperado }\end{array}$ \\
\hline D64 & $\begin{array}{l}\text { Tempo de resposta da empresa às demandas do } \\
\text { mercado (certificações, tecnologias diferenciadas, } \\
\text { etc.) }\end{array}$ & $\begin{array}{l}\text { Segue a tendência } \\
\text { do mercado }\end{array}$ & $\begin{array}{l}\text { Antecipa-se às } \\
\text { demandas do } \\
\text { mercado }\end{array}$ \\
\hline D65 & Quadro de funcionários dos últimos três anos & $\begin{array}{l}\text { Diminuiu muito } \\
(<50 \%)\end{array}$ & $\begin{array}{l}\text { Aumentou muito } \\
\text { (>50\%) }\end{array}$ \\
\hline D66 & $\begin{array}{l}\text { Capacidade da empresa em se adaptar às mudanças de } \\
\text { seu mercado/ambiente }\end{array}$ & Nenhuma & $\begin{array}{l}\text { Forte capacidade } \\
\text { de adaptação }\end{array}$ \\
\hline D67 & Produtividade das atividades realizadas & Abaixo da média & $\begin{array}{l}\text { Muito acima da } \\
\text { média }\end{array}$ \\
\hline D68 & $\begin{array}{l}\text { Quantidade de problemas detectados durante a } \\
\text { execução dos serviços/obras }\end{array}$ & Inexistente & Muito grande \\
\hline D69 & Lucratividade do negócio & Nenhuma & Muito alta \\
\hline D70 & $\begin{array}{l}\text { Adaptação em caso de mudanças não previstas na } \\
\text { execução das obras/serviços }\end{array}$ & Baixa & Alta \\
\hline D71 & $\begin{array}{l}\text { Preocupação com o impacto da atividade do produto } \\
\text { no meio ambiente }\end{array}$ & Nenhuma & Muito alta \\
\hline D72 & $\begin{array}{l}\text { Preocupação com o bem-estar e a segurança dos } \\
\text { funcionários }\end{array}$ & Nenhuma & Muito grande \\
\hline D73 & Taxa de crescimento da empresa nos últimos três anos & Zero & $>10 \%$ \\
\hline
\end{tabular}

Quadro 6 - Relação com o cliente/fornecedor

\begin{tabular}{|c|l|l|l|}
\hline Legenda & \multicolumn{1}{|c|}{ Relação com o cliente/fornecedor } & Extremo inferior & Extremo superior \\
\hline L74 & Tipo de contrato com o cliente & Curto prazo & Longo prazo \\
\hline L75 & $\begin{array}{l}\text { Ocorrência de ações conjuntas para a redução dos } \\
\text { prazos de execução da obra }\end{array}$ & Nunca & Permanentemente \\
\hline L76 & $\begin{array}{l}\text { Mudanças na produção devido às } \\
\text { solicitações/especificações dos clientes }\end{array}$ & Frequentes & Nunca ocorrem \\
\hline L77 & $\begin{array}{l}\text { Comunicação de alterações de projeto/especificações } \\
\text { aos clientes }\end{array}$ & Frequentes & Nunca ocorrem \\
\hline L78 & $\begin{array}{l}\text { Discussão sobre problemas de qualidade com os } \\
\text { clientes }\end{array}$ & Frequentes & Nunca ocorrem \\
\hline L79 & Busca de soluções com a cooperação do cliente & Frequentes & Nunca ocorrem \\
\hline L80 & Preços cobrados pelos serviços/empreendimentos & $\begin{array}{l}\text { Abaixo do } \\
\text { mercado }\end{array}$ & Acima do mercado \\
\hline L81 & Respeito dos prazos contratados para pagamentos & Ocorre sempre & Nunca ocorre \\
\hline L82 & $\begin{array}{l}\text { Busca de informações junto aos fornecedores visando } \\
\text { otimizar a gestão dos estoques da empresa }\end{array}$ & Frequentes & Nunca ocorrem \\
\hline L83 & Preços contratados são rediscutidos & Nunca & Sempre \\
\hline L84 & Valores ofertados segundo a percepção dos clientes & Baixos & Altos \\
\hline L85 & $\begin{array}{l}\text { Satisfação do cliente com relação ao serviço } \\
\text { executado/entrega do produto }\end{array}$ & Baixa & Alta \\
\hline
\end{tabular}

O método Micmac, criado por Michel Godet, é composto das seguintes fases: listagem das variáveis, descrição das relações entre as variáveis, definição da matriz estrutural e classificação das inter-relações. (a) listagem das variáveis: foram utilizadas todas as variáveis listadas nos Quadros 2, 3, 4, 5 e 6;

(b) descrição das relações entre as variáveis: as relações entre as variáveis foram obtidas a partir da correlação matemática entre elas. Para obtê-las, os dados coletados por meio dos questionários foram 
primeiramente lançados numa planilha do Microsoft Office Excel e posteriormente tratados e analisados pelo software SPSS (Statistical Package for the Social Sciences). Com o uso do SPSS foram obtidas as correlações entre todas as variáveis, utilizando o coeficiente de Spearman, que é o mais indicado para dados não paramétricos. O coeficiente de Spearman mede a intensidade de relação entre as variáveis ordinais. O coeficiente varia entre -1 e 1 , e quanto mais próximo estiver desses extremos, maior será a associação entre as variáveis. O sinal negativo significa que a variação está em sentido contrário, ou seja, o "aumento” no valor de uma variável causa a redução do valor da outra;

(c) definição da matriz estrutural: a matriz estrutural é a matriz que mostra a existência ou não de relação entre as variáveis. Ela é definida a partir dos coeficientes de correlação obtidos na etapa anterior; e

(d) classificação das inter-relações: ela pode ser obtida com o auxílio do software MicMac Lipsor, que permite implementar o método Micmac. $\mathrm{O}$ resultado alcançado é uma classificação das variáveis em quatro grupos (quadrantes): variáveis motrizes, variáveis críticas (motrizes e dependentes), variáveis dependentes e variáveis independentes. A partir da posição de cada variável na classificação é possível avaliar sua importância relativa na estrutura (classificação direta) na dinâmica do sistema (classificação indireta).

\section{Resultados e discussões}

A Tabela 1 apresenta a correlação das variáveis logísticas com as outras características da empresa: organização, estratégia, desempenho e ambiente concorrencial. O sinal negativo representa que a variável é inversamente relacionada com a outra extremidade da questão em análise. O sinal gráfico de um asterisco $(*)$ representa que a correlação é significativa no nível 0,05 , e de dois asteriscos $(* *)$ que é significativa no nível 0,01 , sendo válida nas duas extremidades.

A Tabela 2 apresenta o grau de correlação entre as variáveis e os pesos de influência adotados nas análises a partir das recomendações propostas por Hair Junior et al. (2005).

Com base nos valores das correlações entre todas as variáveis foi elaborada a matriz de influências para dar início à aplicação do método Micmac. Para a construção da matriz de influências diretas são atribuídos os valores de 0 a 3 , que representam o peso de influência (Tabela 2). O valor de 0 a 3 é uma recomendação do método Micmac. A matriz é preenchida da linha para a coluna e indica a influência que a variável da linha exerce sobre as variáveis das colunas. A diagonal principal é igual a 0 , pois não é considerada a influência da variável sobre ela mesma.

\section{Análise da Influência Direta entre as Variáveis}

Com a matriz de influências diretas, o método gera o gráfico de influências, que é a demonstração das inter-relações estabelecidas das variáveis representadas por linhas de cores, espessuras e texturas diferentes (Quadro 7).

Devido ao grande número de variáveis e suas correlações, para melhor visualização das maiores influências, o gráfico de influências diretas, representado pela Figura 2, é a demonstração de $10 \%$ dessas influências, sendo duas variáveis logísticas destacadas como mais importantes (linha vermelha); as mudanças na produção devem-se às solicitações/especificações dos clientes (L76), atuando na comunicação de alterações de projetos/especificações aos clientes (L77).

Outras influências importantes ocorrem entre as variáveis de estratégia: o nível de preocupação da empresa em relação à adoção de melhorias nos processos gerenciais (E48), o que influencia mutuamente o nível de preocupação da empresa, em relação à prevenção de problemas, na execução de seus empreendimentos (E49), e denota a grande interdependência existente entre ambas; o nível de conhecimento dos funcionários em relação às estratégias de gestão, adotadas pela empresa (E47), o que instiga o nível de preocupação em relação à adoção de melhorias nos processos gerenciais (E48); os procedimentos gerenciais definidos para orientar os funcionários em suas atividades (E57), realçando a preocupação com a verificação dos processos gerenciais relacionados ao desenvolvimento das atividades (E58); e a preocupação com a implantação de inovações em seus empreendimentos (E45), o que influencia a aquisição de novas tecnologias (E54).

\section{Análise do Mapa de Influência e Dependência Direta}

O diagrama da Figura 3 fornece como resultado o agrupamento e a classificação das variáveis estudadas, de acordo com a relação de influência, de dependência direta delas, divididas em quatro quadrantes. 
Tabela 1 - Correlação entre as variáveis

\begin{tabular}{|c|c|c|c|c|c|c|c|c|c|c|c|c|}
\hline & L74 & \begin{tabular}{|l} 
L75 \\
\end{tabular} & L76 & L77 & L78 & L79 & \begin{tabular}{|l|} 
L80 \\
\end{tabular} & L81 & L82 & L83 & L84 & L85 \\
\hline C29 &,- 011 &,- 095 & ,056 & ,111 &,- 174 &,- 150 & \begin{tabular}{|l}
,- 035 \\
\end{tabular} & ,024 &,- 085 & ,015 & ,192 &,- 161 \\
\hline C30 & ,031 & ,043 &, $280^{*}$ &, $263^{*}$ & ,165 &, $381^{* *}$ & \begin{tabular}{|l|}
,- 016 \\
\end{tabular} & 0,04 & ,022 &,- 098 & ,035 &,$- 254^{*}$ \\
\hline C31 & ,072 & ,139 &,- 130 &,- 199 &,- 096 &,- 117 &,- 011 &,- 076 &,- 033 &, $238^{*}$ & ,061 & ,165 \\
\hline C32 & ,096 &, $375^{* *}$ & ,087 & ,072 & ,044 & ,001 & ,074 &,- 166 &,$- 344^{* *}$ &,- 031 &,- 006 & ,208 \\
\hline C33 & ,058 & ,177 & ,180 & ,268 & ,168 &, $261^{*}$ &, $247^{*}$ &,- 183 &,- 181 & ,005 &, $253^{*}$ &,- 101 \\
\hline C34 & ,051 & ,154 & ,073 &,- 008 & ,123 &,- 005 & ,148 &,- 116 &,$- 332^{* *}$ &,- 057 & $365^{* *}$ & 0,218 \\
\hline C35 &,- 001 &, $285^{*}$ &, $258^{*}$ & ,209 & ,194 & ,068 & ,051 &,- 094 &,$- 367^{* *}$ &,- 131 &,- 122 & ,090 \\
\hline C36 & ,132 &, $234^{*}$ & ,008 &,- 196 &,- 108 &,$- 273^{*}$ &,- 030 &,- 060 &,- 115 & ,042 & ,007 & ,227 \\
\hline C37 & $\begin{array}{l}, 049 \\
\end{array}$ & ,125 & ,139 & ,055 & \begin{tabular}{|l|}
, 103 \\
\end{tabular} & ,057 & \begin{tabular}{|l|}
,- 079 \\
\end{tabular} & \begin{tabular}{|l|}
, 074 \\
\end{tabular} & , 029 &, $268^{*}$ &,- 113 &,- 042 \\
\hline C38 & ,065 & 0,22 & ,025 &,- 132 &,- 051 &,- 111 & ,171 &,- 181 &,- 009 & ,196 & 0,211 & 198 \\
\hline C39 & ,024 & \begin{tabular}{|l|}
, 088 \\
\end{tabular} &,- 053 & ,002 &,- 048 & ,014 & ,087 &,$- 237^{*}$ &,$- 371^{* *}$ & ,101 &,- 062 & ,072 \\
\hline C40 &,- 217 &,- 038 & ,058 & ,080 & ,027 & ,108 &,- 091 & ,041 &,- 225 & ,031 &,$- 310^{* *}$ & ,104 \\
\hline C41 & ,013 &, $317^{* *}$ &,- 121 &,$- 308^{* *}$ &,$- 234^{*}$ &,$- 292^{*}$ & ,086 &,- 230 &,- 163 & ,084 & ,136 &, $242^{*}$ \\
\hline C42 &,- 231 &,$- 273^{*}$ &,- 198 &,- 187 &,- 139 & ,045 &,- 143 & ,063 & ,035 &,- 086 & ,022 & ,047 \\
\hline C43 &, 047 & ,115 &,- 113 &,$- 266^{*}$ &,$- 232^{*}$ &,- 160 &,$- 320^{* *}$ & ,103 &,- 087 & 140 &,- 049 & ,165 \\
\hline E44 & ,017 & ,112 &,- 035 &,- 035 & ,112 & ,040 & $-0,04$ &,- 193 & ,097 & ,118 &,- 069 & ,120 \\
\hline E45 & ,032 &, $264^{*}$ &,- 074 &,$- 246^{*}$ &,- 158 &,- 204 &, $300^{*}$ &,- 227 &,- 227 & ,221 & ,194 & ,221 \\
\hline E46 &,- 035 &, $370^{* *}$ & ,024 &,- 111 & ,054 &,- 090 & ,221 &,- 206 &,$- 343^{* *}$ &, 150 &, $268^{*}$ &, $298^{*}$ \\
\hline E47 & 085 &, $371^{* *}$ & ,057 &,- 056 &,- 058 &,- 087 & ,017 &,- 082 &,$- 242^{*}$ & ,141 & ,042 & ,188 \\
\hline E48 & ,080 &, $562^{* *}$ & ,137 & ,097 & ,168 & \begin{tabular}{|l|}
,- 032 \\
\end{tabular} & ,160 & \begin{tabular}{|l|}
,- 191 \\
\end{tabular} &,$- 337^{* *}$ &, 114 & ,027 &, $272^{*}$ \\
\hline E49 &,- 006 &, $508^{* *}$ & ,097 & ,000 & ,085 &,- 112 &, $247^{*}$ &,$- 376^{* *}$ &,$- 418^{* *}$ & ,008 & ,089 &, $363^{* *}$ \\
\hline E50 & ,145 &, $335^{* *}$ &,- 090 &,- 082 &,- 075 &,$- 336^{* *}$ & ,175 &,- 197 &,$- 505^{* *}$ &,- 065 & ,226 &, $293^{*}$ \\
\hline E51 & ,113 &, $377^{* *}$ &,- 064 &,- 071 & ,036 &,- 167 & ,157 &,- 075 &,$- 250^{*}$ &, $270^{*}$ &,- 057 &, $321^{* *}$ \\
\hline E52 & ,004 & $375^{* *}$ &,- 145 &,- 229 & 012 &,$- 262^{*}$ &, $313^{* *}$ &,- 222 &,$- 297^{*}$ &,- 017 & ,160 &, $480^{* *}$ \\
\hline E53 & , 143 & \begin{tabular}{|l|}
, 211 \\
\end{tabular} & \begin{tabular}{|l}
, 072 \\
\end{tabular} &,$- 287^{*}$ & $\begin{array}{l}-, 100 \\
\end{array}$ &,$- 238^{*}$ & \begin{tabular}{|l}
, 158 \\
\end{tabular} & $\frac{1,2 L}{-, 135}$ &,- 191 & 107 & $290^{*}$ &, $394^{* *}$ \\
\hline E54 & 131 &, $273^{*}$ &,- 092 &,- 213 &,- 198 &,$- 270^{*}$ &, $315^{* *}$ &,- 173 &,$- 290^{*}$ & ,159 &, $241^{*}$ & $317^{* *}$ \\
\hline E55 &,- 001 &, $349^{* *}$ &, 004 &,- 088 &,- 040 &,- 149 & \begin{tabular}{|l|}
, 196 \\
\end{tabular} &,- 145 &,$- 290^{*}$ & ,097 &,- 001 &, $282^{*}$ \\
\hline E56 &, $328^{* *}$ &, $436^{* *}$ &,- 121 &,- 124 & $\begin{array}{l}, 077 \\
\end{array}$ &,- 133 & ,132 &,- 214 &,- 227 & ,196 &,- 007 &, $321^{* *}$ \\
\hline E57 & ,211 &, $304^{* *}$ & ,106 & ,069 & ,043 &,- 004 & ,146 &,- 148 &,$- 234^{*}$ & ,013 &,- 035 & ,211 \\
\hline E58 & ,081 & ,216 & ,189 & ,109 & ,100 & ,100 & ,132 &,- 194 &,- 191 &,- 044 &,- 025 &, 150 \\
\hline E59 & ,188 & ,174 & ,132 & ,030 &,- 012 &,- 056 & ,099 &,- 223 &,- 145 &,- 139 &,- 081 & ,024 \\
\hline E60 & $\begin{array}{l}, 071 \\
\end{array}$ &, $282^{*}$ &,- 139 & $\begin{array}{l}-198 \\
-19\end{array}$ &,- 099 &,- 219 &, $252^{*}$ &,$- 291^{*}$ &,$- 283^{*}$ & ,089 & ,028 &, $364^{* *}$ \\
\hline E61 &, $295^{*}$ & 0,141 &,- 047 &,- 078 & 032 &,- 062 & 193 &,- 180 &,- 141 &,- 021 & ,211 &, $263^{*}$ \\
\hline D62 &, $282^{*}$ & \begin{tabular}{|l|}
, $299^{*}$ \\
\end{tabular} & , 039 &,- 115 & $\begin{array}{l}, 056 \\
\end{array}$ &,$- 241^{*}$ & $\begin{array}{l}-, 118 \\
\end{array}$ &,$- 343^{* *}$ &,$- 234^{*}$ &,- 001 & , 128 &, $282^{*}$ \\
\hline D63 & ,148 & , 166 &,- 048 &,- 190 & ,047 &,- 082 & ,194 &,- 227 &,$- 397^{* *}$ &,- 005 &, $278^{*}$ &, $514^{* *}$ \\
\hline D64 & ,190 & ,168 & ,165 & , 051 & ,053 &,- 148 & \begin{tabular}{|l|}
,- 032 \\
\end{tabular} &, 003 &,- 232 & ,057 &, 230 &, $274^{*}$ \\
\hline D65 &,- 098 & ,144 &,- 032 &,- 041 &,- 090 &,- 019 &,- 141 &,- 012 &,- 099 & ,061 &,- 012 & ,134 \\
\hline D66 &,- 068 &, $517^{* *}$ & ,113 & ,005 &,- 014 &,- 054 &,- 006 &,- 200 &,- 051 & 105 & ,040 & 150 \\
\hline D67 & ,029 &, $279^{*}$ & ,157 & ,017 &,- 016 &,- 030 & ,123 &,$- 244^{*}$ &,- 031 & ,026 & ,068 & ,179 \\
\hline D68 &,$- 429^{* *}$ &,$- 356^{* *}$ &,- 113 &,- 030 &,- 118 &, $266^{*}$ &,- 075 & $309^{* *}$ & ,203 & ,067 &,- 125 &,- 230 \\
\hline D69 & ,116 & \begin{tabular}{|l|}
, 175 \\
\end{tabular} & ,099 &,- 022 & 146 & ,051 & ,141 &,$- 251^{*}$ &,$- 246^{*}$ &,- 225 & ,269* & $354^{* *}$ \\
\hline D70 &,- 045 &, $367^{* *}$ &,- 216 &,$- 330^{* *}$ &,- 206 &,$- 311^{* *}$ & 139 &,- 200 &,- 208 & 154 & $361^{* *}$ & ,196 \\
\hline D71 & ,182 &, $502^{* *}$ &,- 051 &,- 119 &,- 076 &,- 103 &, $328^{* *}$ &,- 212 &,$- 253^{*}$ & ,155 & ,183 & ,130 \\
\hline D72 & ,004 &, $308^{* *}$ &,- 204 &,- 192 &,- 169 &,$- 279^{*}$ & \begin{tabular}{|l|}
, 074 \\
\end{tabular} &,- 210 &,$- 301^{* *}$ &, 000 & ,196 &, $320^{* *}$ \\
\hline D73 & ,117 & ,230 & ,005 & ,064 & ,110 & ,037 & ,115 &,- 109 &,- 078 &,- 028 & ,090 & ,139 \\
\hline A1 &,- 189 & ,024 & ,117 & ,118 & ,033 & ,135 &,- 018 &,- 119 &,- 013 & ,159 & ,046 &,- 212 \\
\hline A2 &, $251^{*}$ &,- 023 & ,053 &,- 065 &,- 196 & ,024 & ,029 &,- 056 & ,144 &,- 017 & ,088 &,- 109 \\
\hline A3 &,- 032 & ,167 & ,228 &,- 031 & ,049 &,- 111 & ,202 &,- 036 & ,009 &,- 086 & ,171 & ,126 \\
\hline A4 &, $255^{*}$ &,- 025 & ,041 & ,065 & ,072 &,- 155 & ,036 & 117 & ,000 & 116 &,- 187 & ,091 \\
\hline A5 & ,092 & , 028 & 121 &,- 009 & ,071 & ,037 &, $261^{*}$ &,- 056 &,- 054 &,- 012 & ,010 & $\begin{array}{l}, 018 \\
\end{array}$ \\
\hline A6 & ,094 &,- 073 & \begin{tabular}{|l|}
, 017 \\
\end{tabular} & ,006 &,- 004 &,- 032 & ,298 & ,179 &,- 076 & 146 & 165 &,- 017 \\
\hline A7 &,- 010 & \begin{tabular}{|l}
, 073 \\
\end{tabular} &,- 148 &,- 090 &,$- 282^{*}$ &,- 151 & \begin{tabular}{|l|}
,- 141 \\
\end{tabular} & ,078 &,- 123 &, $335^{* *}$ &,- 134 &, $236^{*}$ \\
\hline A8 &,- 150 & ,059 &,- 011 &,- 094 &,- 218 &,- 048 & ,111 &,- 069 & 105 & ,006 &,- 098 &,- 004 \\
\hline A9 & ,037 & ,125 &,- 007 & ,079 & ,021 & \begin{tabular}{|l|}
,- 078 \\
\end{tabular} &,- 024 &,- 201 &,- 097 &,- 079 & ,041 & ,144 \\
\hline A10 &, $287^{*}$ & ,165 &,$- 322^{* *}$ &,- 155 &,- 052 &,- 099 & ,095 &,- 015 &,- 155 & ,118 & ,040 & ,095 \\
\hline A11 & \begin{tabular}{|l|}
, 081 \\
\end{tabular} & , $250^{*}$ &,- 044 & $\begin{array}{l}-139 \\
\end{array}$ & \begin{tabular}{|l|}
, 020 \\
\end{tabular} &,$- 291^{*}$ & \begin{tabular}{|l|}
, 135 \\
\end{tabular} & $\begin{array}{l}-, 132 \\
\end{array}$ &,$- 276^{*}$ & 060 & 102 & $331^{* *}$ \\
\hline A12 & ,149 &,- 049 &,- 083 &,- 005 & ,006 &,- 213 & ,005 & ,028 &,- 089 &,- 015 &,- 066 &, $247^{*}$ \\
\hline A13 &,- 034 & ,095 &,- 030 &,- 111 &,$- 244^{*}$ &,$- 258^{*}$ & ,053 &,- 008 &,- 141 & 176 & ,116 & ,127 \\
\hline A14 & , 041 & \begin{tabular}{|l}
,- 118 \\
\end{tabular} & \begin{tabular}{|l}
, 008 \\
\end{tabular} & ,126 &,- 116 & 101 & ,054 &, $249^{*}$ & ,150 & 137 & , 035 &,$- 301^{*}$ \\
\hline A15 & ,143 & ,025 &,- 131 &,- 107 &,- 114 &,- 129 & ,090 &,- 161 &,- 152 &,- 050 & 168 & ,155 \\
\hline A16 &, $310^{* *}$ & \begin{tabular}{|l|}
, 086 \\
\end{tabular} &,- 155 &,- 077 &,- 025 & ,105 & ,135 &,$- 240^{*}$ &,- 102 & ,139 & ,177 & ,156 \\
\hline A17 & ,223 & , 076 & , 100 & ,045 &, 025 &,- 027 & 125 &, 064 &,- 116 & 015 &, $269^{*}$ &,- 085 \\
\hline A18 & $391^{* *}$ & ,141 & , 112 &,- 051 & ,003 &,- 197 & ,093 &,- 124 &,- 053 &,- 057 & $261^{*}$ &, $265^{*}$ \\
\hline A19 &,- 009 & ,179 &,- 029 & 020 &,- 011 &,- 102 & ,029 &,- 123 & ,009 &, 224 &,- 061 &, $314^{* *}$ \\
\hline A20 & ,154 &, $414^{* *}$ & \begin{tabular}{|l|}
, 095 \\
\end{tabular} & 148 & \begin{tabular}{|l|}
, 199 \\
\end{tabular} & ,006 & $322^{* *}$ & \begin{tabular}{|l|}
,- 179 \\
\end{tabular} &,$- 270^{*}$ & ,083 & ,226 & $285^{*}$ \\
\hline A21 & ,190 &, $348^{* *}$ & \begin{tabular}{|l}
, 005 \\
\end{tabular} &,- 066 &,- 027 &,- 050 & \begin{tabular}{|l|}
, 059 \\
\end{tabular} &,$- 262^{*}$ &,- 054 &,- 014 &,- 058 & $237^{*}$ \\
\hline A22 & ,005 & \begin{tabular}{|l|}
, 072 \\
\end{tabular} &,- 057 &,- 004 &,- 058 &,- 061 & \begin{tabular}{|l}
,- 070 \\
\end{tabular} & ,022 &,- 076 & 146 &,- 204 & 154 \\
\hline A23 & 080 & ,014 & \begin{tabular}{|l|}
,- 225 \\
\end{tabular} &,$- 309^{* *}$ &,- 135 &,- 132 & ,022 & ,074 &,- 056 & 166 & -,031 & 185 \\
\hline A24 & ,152 &,- 051 &,- 130 &,- 150 &,- 064 &,- 055 & ,024 & ,112 &,- 100 & ,136 & ,188 & ,130 \\
\hline A25 & ,028 &, 214 & ,139 & ,133 & , 106 &,- 017 & ,048 & $\begin{array}{l}-, 159 \\
\end{array}$ &,$- 340^{* *}$ &, 114 & ,174 &, $279^{*}$ \\
\hline A26 & 190 & ,055 & ,194 & 137 & ,208 & ,057 & 191 &,$- 255^{*}$ &,- 121 &,$- 237^{*}$ & ,164 & ,068 \\
\hline A27 &, $303^{*}$ &,- 046 & ,131 & 095 & ,134 & ,030 & \begin{tabular}{|l}
,- 053 \\
\end{tabular} & 034 & ,111 & ,096 & ,026 &,- 003 \\
\hline A28 &,- 025 & ,051 & ,021 &,- 024 & 036 & 190 &,- 091 &,- 090 &,- 076 &, $272^{*}$ &,- 111 &, 003 \\
\hline
\end{tabular}

Fonte: SPSS (2018). 
Tabela 2 - Representação dos coeficientes de correlação e Micmac

\begin{tabular}{l|l|l|l|c}
\hline Variação do coeficiente & Força da associação & Cor & Nível de influência & Valores Micmac \\
\hline até $\pm 0,209$ & Leve & Branca & Sem & 0 \\
$\pm 0,210- \pm 0,399$ & Pequena & Verde & Fraca & 1 \\
$\pm 0,400- \pm 0,709$ & Moderada & Amarela & Média & 2 \\
Acima $\pm 0,709$ & Alta & Vermelha & Forte & 3 \\
\hline
\end{tabular}

Fonte: adaptado de Hair J unior et al. (2005).

Quadro 7 - Representação das inter-relações

\begin{tabular}{|l|l|}
\hline \multicolumn{1}{|c|}{ Influência } & \multicolumn{1}{c|}{ Linha } \\
\hline Muito fraca & Preta tracejada \\
\hline Fraca & Preta contínua \\
\hline Média & Azul fina \\
\hline Forte & Azul grossa \\
\hline Mais importante & Vermelha \\
\hline
\end{tabular}

Figura 2 - Gráfico de influências diretas (10\%)

Gráfico de influências diretas

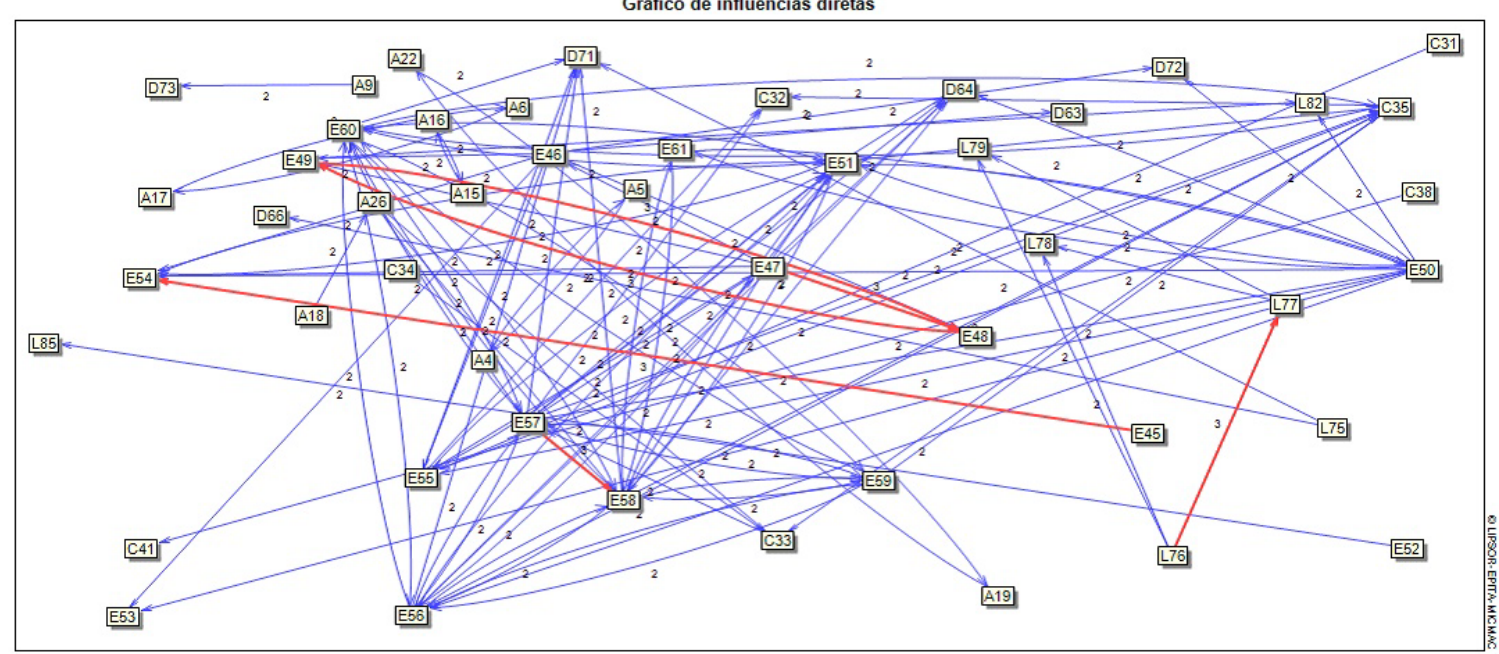

Fonte: software Micmac (GODET, 2016).

Nota: Legenda:

Influências mais fracas

— Influências fracas

— influências médias

- Influências fortes

- Influências mais importantes 
Figura 3 - Mapa de influências/dependências diretas

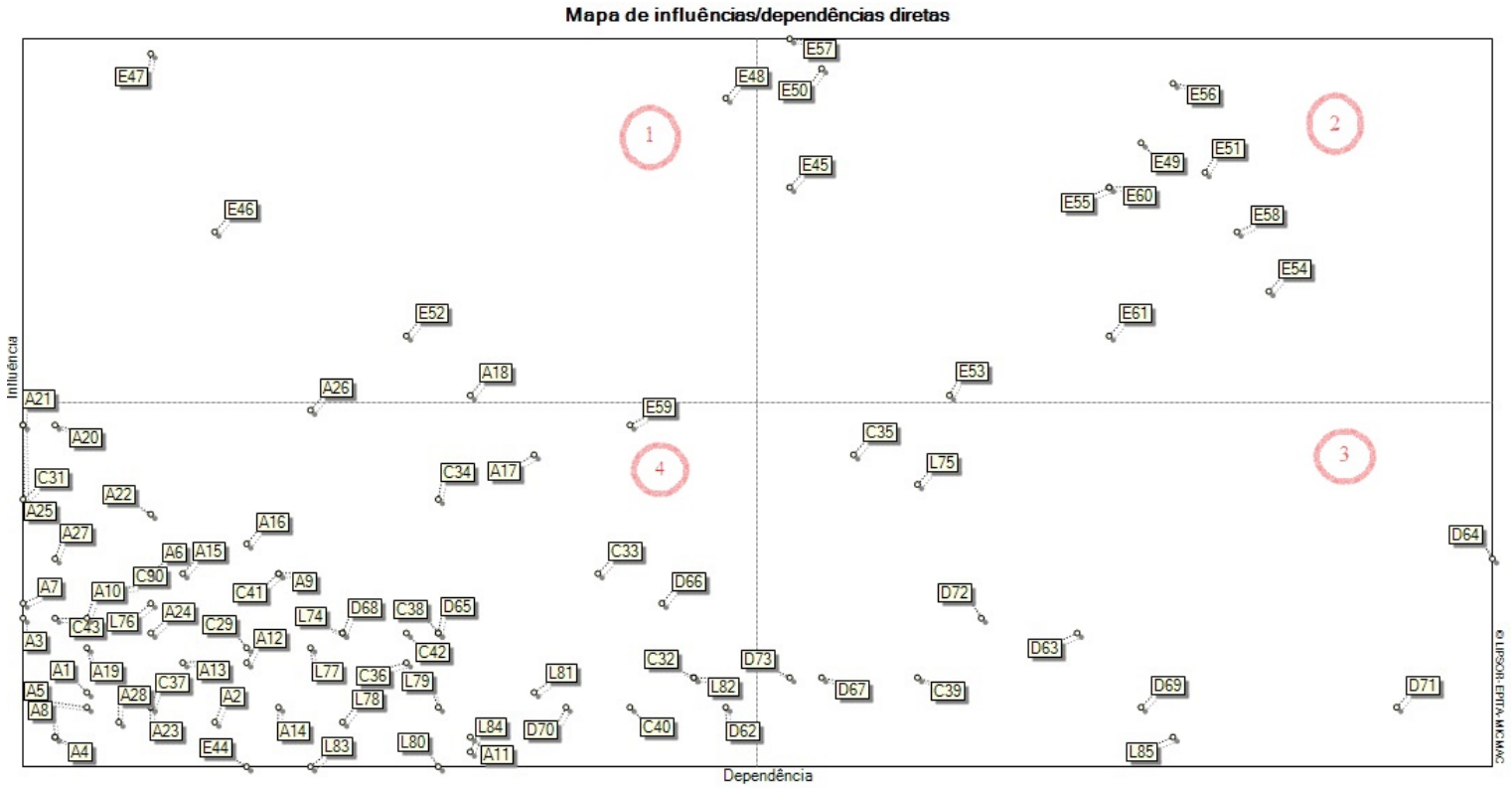

Fonte: software Micmac (GODET, 2016).

No quadrante 1 encontram-se variáveis muito influentes e pouco dependentes, ou seja, as variáveis atuam condicionando o resto do sistema. São elas: o nível de conhecimento dos funcionários em relação às estratégias de gestão adotadas pela empresa (E47); o alinhamento das características dos empreendimentos, produtos ou serviços com a estratégia adotada pela empresa (E46); as instalações/equipamentos adequados às atividades executadas (E52); o nível de preocupação da empresa em relação à adoção de melhorias nos processos gerenciais (E48); e a importância da "marca” para os clientes (A18).

O quadrante 2 é composto das variáveis muito influentes e muito dependentes, chamadas de “variáveis críticas”, pela instabilidade que geram no sistema. Elas podem modificar e ser modificadas pelo sistema. Neste quadrante encontra-se a maioria das variáveis de estratégias e funcionamento: procedimentos gerenciais definidos para orientar os funcionários e suas atividades (E57); investimentos em tecnologias e equipamentos realizado nos últimos três anos (E50); implantação de inovações em seus empreendimentos, produtos ou serviços (E45); conhecimento exigido dos funcionários sobre técnicas utilizadas no desenvolvimento das atividades (E56); prevenção de problemas na execução de seus empreendimentos ou serviços (E49); controle dos processos da empresa terceirizada em seguir a padronização (E60); avaliação das habilidades necessárias aos funcionários para a execução de suas atividades (E51); sistemas de gestão e controle das atividades (E55); verificação (check-list) dos processos gerenciais relacionados ao desenvolvimento das atividades (E58); diferenciação dos serviços da empresa em relação a outras empresas do setor (E61); aquisição de novas tecnologias (E54); e oferta de novos produtos e serviços (E53).

O quadrante 3 é o das variáveis com pouca influência e muito dependentes, ou seja, são os fatores de resultados, representados pelas variáveis de tempo de resposta da empresa às demandas do mercado (D64); pelo impacto da atividade do produto no meio ambiente (D71); pela lucratividade do negócio (D69); pela qualidade do serviço entregue ao cliente (D63); pelo bem-estar e segurança dos funcionários (D72); pela produtividade das atividades realizadas (D67); pela taxa de crescimento da empresa nos últimos três anos (D73); pela satisfação do cliente em relação ao empreendimento (L85); pelas ações conjuntas para redução dos prazos de execução da obra (L75); pela quantidade de horas de treinamento dos funcionários por ano (C39); e pela formalização das atividades e seus processos envolvidos na execução (C35).

O quadrante 4 apresenta as "variáveis independentes”, ou seja, que têm pouca influência e pouca dependência, que demonstram pouco efeito na dinâmica do sistema. A maioria das variáveis logísticas encontra-se neste quadrante e conduz a uma reflexão de como as construtoras ainda não estão visualizando e utilizando os instrumentos logísticos como fator de melhoria em sua produtividade, o que geraria maiores lucros e, 
consequentemente, melhoria na competividade no mercado em que atuam.

\section{Análise de influência indireta entre as variáveis}

O gráfico de influências indiretas é construído a partir das multiplicações sucessivas da matriz de influência direta por ela mesma até atingir a estabilidade, em que a sequência de ordenamento das variáveis (classificação por motricidade e dependência) permanece estável, ou seja, não se altera mais.

Devido à grande quantidade de influências indiretas e para melhor visualização das influências mais importantes, a Figura 4 representa apenas 1\% do gráfico de influências indiretas.

Observando as influências mais importantes (linha vermelha), é possível inferir que a variável estratégica referente aos procedimentos gerenciais definidos para orientar os funcionários em suas atividades (E57) influencia indiretamente três variáveis: tempo de resposta da empresa às demandas do mercado (D64); preocupação com a aquisição de novas tecnologias (E54); e preocupação com o impacto da atividade do produto no meio ambiente (D71).

\section{Análise do mapa de influência e dependência indireta}

O passo seguinte é a análise do mapa de influências e dependências indiretas mostrado na Figura 5. O resultado obtido demonstra pequenas alterações na posição de quase todas as variáveis.

O quadrante 1 , das variáveis motrizes, que tem muita influência no sistema, é composto apenas de elementos estratégicos, assim como o quadrante 2 , das variáveis críticas. A maioria das variáveis logísticas continuam como variáveis independentes (quadrante 4), com exceção das variáveis ações conjuntas para a redução dos prazos de execução da obra (L75) e satisfação do cliente com relação ao empreendimento (L85), que continuam no quadrante 3 , das variáveis dependentes.

A Figura 6 mostra o mapa de deslocamento de influências e dependências das variáveis diretas para indiretas. É possível verificar que não existe um deslocamento expressivo, o que demonstra que as variáveis têm uma posição relativamente estável de influências e dependências.

A variável de estratégia nível de preocupação da empresa em relação à adoção de melhorias nos processos gerenciais (E48), definida como motriz no mapa direto, passou a ser crítica no mapa indireto, ou seja, indiretamente ele passa a ser muito dependente também.

O deslocamento das variáveis instalações/ equipamentos existentes adequados às atividades executadas (E52) e a importância da marca para os clientes (A18), de motrizes para independentes, são considerados pequenos, pois as variáveis estavam próximas do limite entre os quadrantes.

Figura 4 - Gráfico de influências indiretas (1\%)

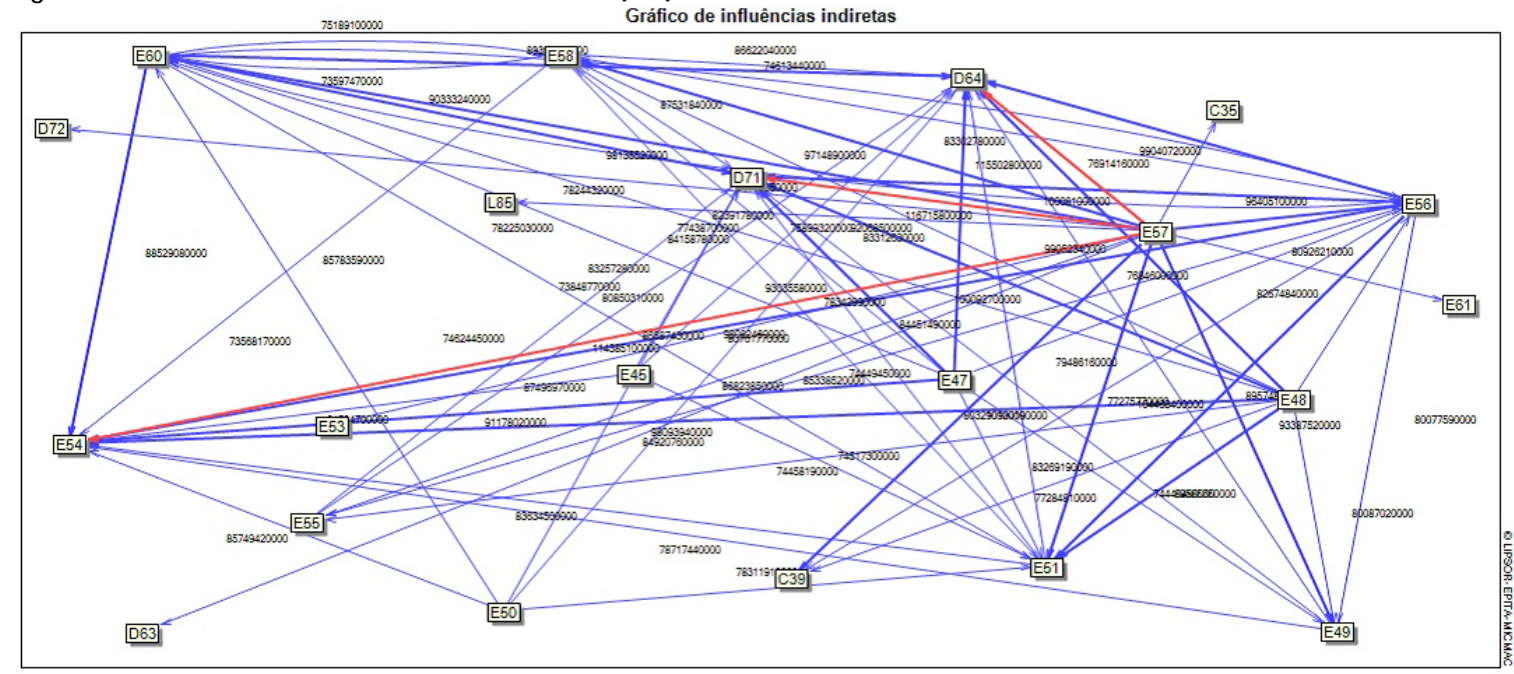

Fonte: software Micmac (GODET, 2016).

Nota: Legenda:

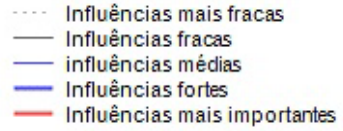


Figura 5 - Mapa de influências/dependências indiretas

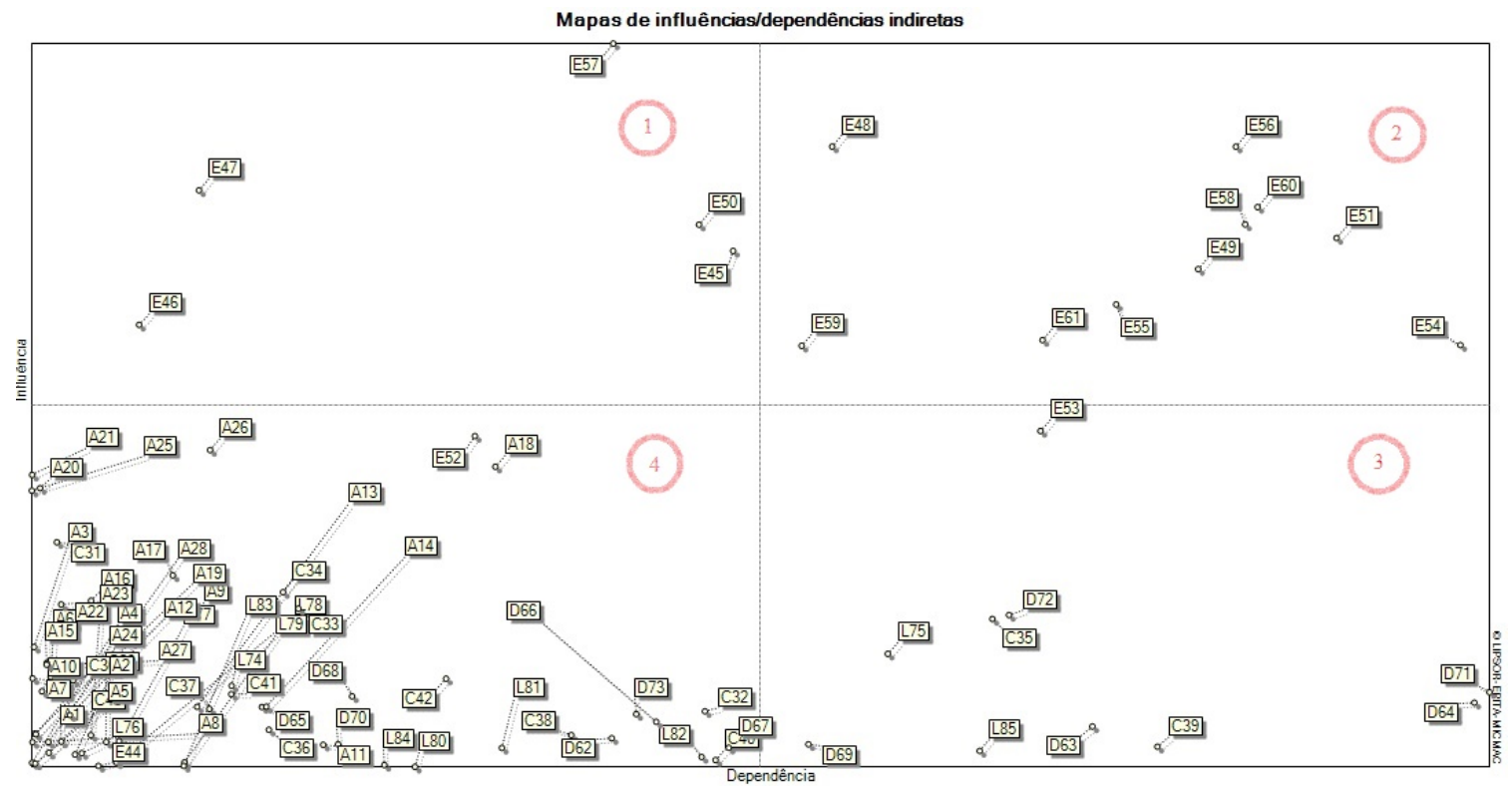

Fonte: software Micmac (GODET, 2016).

\section{Figura 6 - Mapa de deslocamentos: direto/indireto}

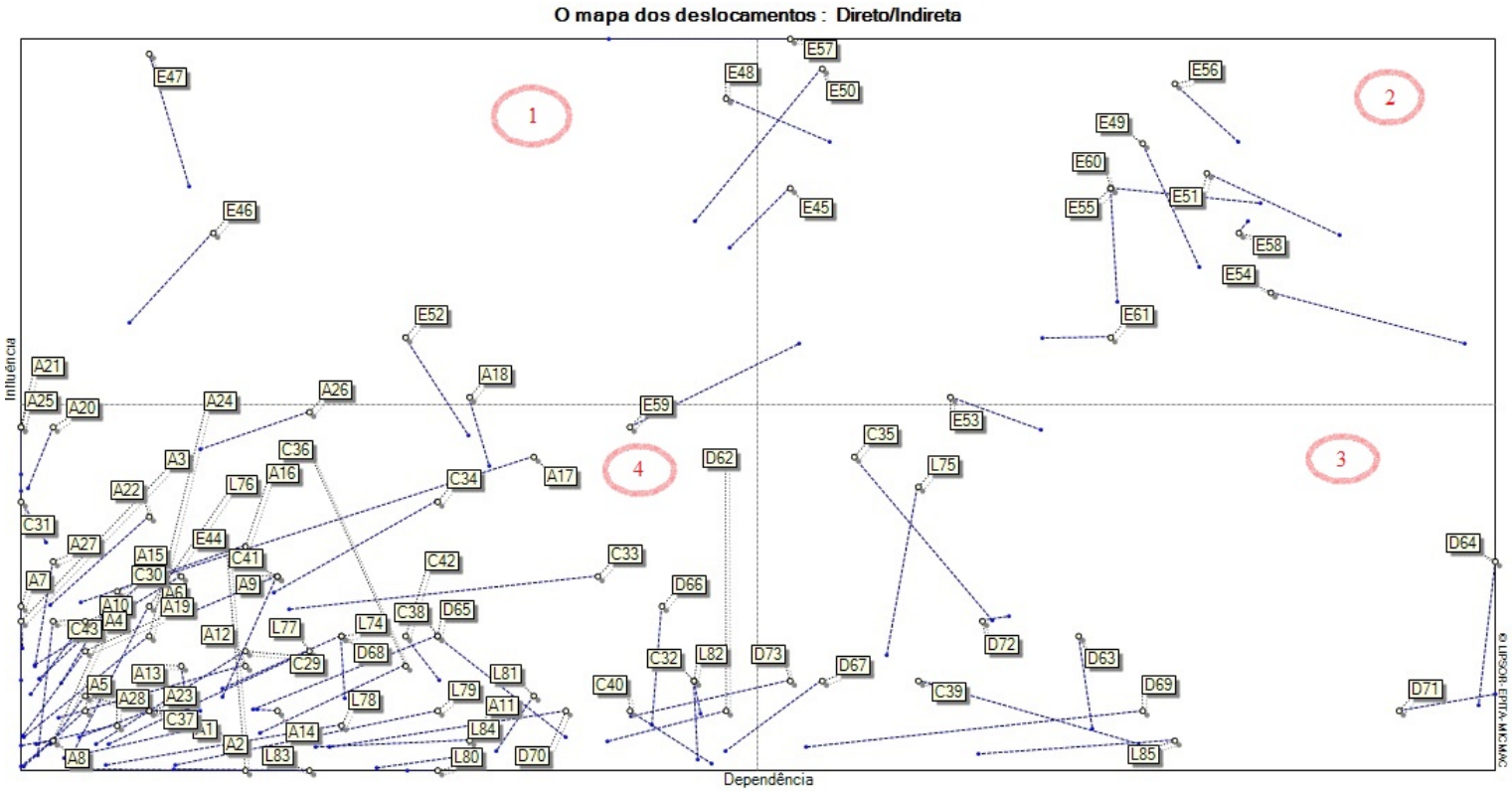

Fonte: software Micmac (GODET, 2016).

O mesmo ocorre com os deslocamentos das variáveis estratégicas do quadrante que são críticas para motrizes: nível de investimento em tecnologias e equipamentos realizado nos últimos três anos (E50); procedimentos gerenciais definidos para orientar os funcionários em suas atividades (E57); e preocupação com a implantação de inovações em seus empreendimentos (E45). Todas elas se encontram perto dos limites que dividem os quadrantes.
A variável preocupação com a oferta de novos produtos e serviços (E53) se encontra, no mapa, diretamente no quadrante crítico. Entretanto, está perto do limite que divide para o quadrante de dependentes, e no mapa indireto desloca-se para este quadrante.

A maior mudança ocorre na variável referente ao controle de informações sobre as atividades (E59), que sai do quadrante direto independente para o quadrante indireto crítico. 


\section{Discussão dos resultados}

Ao estudar as correlações das variáveis logísticas com a organização, desempenho, estratégias e ambiente concorrencial, fica destacada a importância de três variáveis logísticas: as ações conjuntas para a redução dos prazos (L75), a busca de informações junto a fornecedores (L82) e a satisfação do cliente em função do serviço executado (L85). Essas variáveis se relacionam com três aspectos básicos e necessários ao funcionamento na eficiência do sistema logístico: cooperação, planejamento e resultado.

As ações conjuntas para a redução dos prazos de execução da obra (L75) estão altamente correlacionadas com as variáveis estratégicas e de desempenho da organização. As maiores correlações são em relação à adoção de melhorias nos processos gerenciais (+0,562/E48), prevenção de problemas na execução de seus empreendimentos (+0,508/E49), capacidade da empresa em se adaptar às mudanças (+0,517/D66) e preocupação com o impacto da atividade do produto no meio ambiente (+0,502/D71). As ações conjuntas para a redução dos prazos estão relacionadas com praticamente todas as variáveis estratégicas e de desempenho. Isso demostra que a cooperação deve ter uma sustentação estratégica para que possa dar resultado. $\mathrm{O}$ artigo de Love et al. (2002) sugere que a logística deve ter sua implementação baseada nas relações estratégicas com foco no cliente e no fornecedor.

As correlações com as características organizacionais mostram que as ações conjuntas para redução de prazos são influenciadas por uma estrutura favorável (integração e formalização de atividades e processos) e por um ambiente propício de relações humanas (autonomia, interação e informalidade dos funcionários da organização).

A variável relacionada à busca de informações junto a fornecedores (L82) caracteriza uma ação proativa da logística. Ela está correlacionada com praticamente todas as variáveis estratégicas e num grau menor com as variáveis de desempenho e características organizacionais. Com relação à estratégia, destaca-se a forte correlação com o nível de investimentos em tecnologias e equipamentos realizado nos últimos anos (-0,505/E50). A razão dessa forte correlação deriva provavelmente da necessidade de tecnologias de informação e comunicação, como suporte para a implementação dessa ação. No que diz respeito ao desempenho, como era de se esperar, a ação proativa em relação à logística tem um efeito na qualidade final do empreendimento (+0,397/D63). Do ponto de vista das características organizacionais, as variáveis que mais se destacam estão relacionadas à gestão dos recursos humanos (treinamento, formalização dos cargos e controle de funcionários) e à formalização da estrutura (integração entre processos e formalização de atividades e processos). Essas características são típicas de organizações que passam por um processo de implementação de sistemas integrados de gestão baseados em tecnologias da comunicação e informação.

A importância das variáveis logísticas "busca de informações junto aos fornecedores visando otimizar a gestão do estoque" (L82) e "permanência de ações conjuntas para a redução dos prazos de execução de obra” (L75) já eram ressaltadas nos resultados da análise do artigo de Akintoye, McIntosh e Fitzgerald (2000), em que indicam um número significativo de crescimento de formação de parcerias entre construtores, fornecedores e clientes, e enfatizam as virtudes dessas parcerias de longo prazo nos ganhos substanciais de produtividade para a indústria.

A variável logística "satisfação do cliente em função do serviço executado” (L85) reforça que os resultados das ações logísticas são fortemente influenciados pela estratégia e, no caso desta variável, pelas características do ambiente concorrencial. Como nas variáveis anteriores, a satisfação do cliente com o serviço é influenciada por praticamente todas as variáveis estratégicas. O destaque vai para a adequação das instalações/equipamentos para com as atividades executadas com uma correlação de 0,480. Essa variável sofre uma nítida influência do nível de competição entre as empresas (A19/0,314) e é afetada mais positivamente quando as vendas são de uma forma mais direta (A14/-0,301). A taxa de retorno dos clientes (A11), que aparece com uma correlação de 0,331 , pode ser considerada uma variável de controle, ou seja, quando a satisfação aumenta, a taxa de retorno também aumenta e viceversa.

A análise das variáveis logísticas que mais se destacaram (L75, L82 e L85) mostra que o desempenho da organização acaba sendo uma consequência da ação logística. A correlação entre logística e desempenho é descrita no artigo de Vidalakis, Tookey e Sommerville (2011), em que relatam que as práticas da gestão de cadeia de suprimentos ajudam a melhorar o desempenho das empresas de construção. Alguns exemplos dessa forte correlação entre as variáveis logísticas e as variáveis de desempenho são satisfação do cliente (L85) com qualidade entregue (D63/0,514), ações conjuntas para redução do prazo (L75) com adaptação às mudanças (D70/0,517), com impacto no meio ambiente (D71/0,502). 
O artigo de Papadopoulos et al. (2016) igualmente evidencia a relação do desempenho com a organização quando relata as vantagens competitivas entre a integração entre fornecedores, empreiteiros e clientes. A estratégia de participação dos fornecedores (L82) influencia os resultados comerciais tangíveis e os níveis de satisfação do cliente (L85). As variáveis de permanência de ações conjuntas para redução dos prazos (L75) e as frequentes buscas de informações junto aos fornecedores visando otimizar a gestão dos estoques (L82) são questões que demonstram a visão das empresas de construção em procurar ter uma relação de parceria com os fornecedores.

Ao observar o mapa de influências e dependências no método Micmac, fica evidente que as variáveis logísticas são resultado de uma ação estratégica, e não de ações isoladas das organizações. A variável “ações conjuntas para a redução dos prazos” (L75), que representa a essência da cooperação e parceria na cadeia de suprimentos, aparece no quadrante de varáveis dependentes. A variável "satisfação do cliente em função do serviço executado” (L85) também aparece nesse quadrante, o que reforça seu aspecto de "resultado" em função de outras ações. As demais variáveis logísticas situam-se na parte inferior do quadrante de "variáveis independentes". Isso demostra sua dependência de decisões tomadas em outras instâncias.

A predominância sobre a logística (e sobre outros grupos de variáveis) está a cargo das variáveis estratégicas. A análise do mapa de influências/dependências diretas e indiretas mostra que as variáveis de estratégias têm um papel determinante no comportamento dos outros grupos de variáveis, com destaque sobre as variáveis de desempenho situadas no "quadrante de dependências”. As variáveis estratégicas estão concentradas no quadrante de "variáveis críticas" (muito influentes e muito dependentes) e no quadrante de "variáveis motrizes" (muito influentes).

No caso específico da logística, a configuração do mapa de influências/dependências diretas e indiretas mostra que as decisões estratégicas da organização afetam diretamente duas variáveis logísticas: as ações conjuntas para redução dos prazos de execução da obra (L75) e a satisfação do cliente com relação ao serviço executado/entrega do produto (L85). A primeira está relacionada à iniciativa de ações que a organização pode implementar nas relações entre seus fornecedores de produtos e/ou serviços. A segunda é o resultado dessas ações. Isso ilustra o efeito direto que têm as ações de logística no resultado obtido pela organização.

A variável "busca de informações junto aos fornecedores visando otimizar a gestão dos estoques da empresa” (L82) aparece bem próxima à região de dependência. Isso significa que ela também é bastante afetada pelas decisões estratégicas.

Em síntese, a análise de motricidade/dependência das variáveis mostra que as variáveis logísticas não têm o papel de protagonistas, mas são sensíveis às decisões tomadas nos níveis mais altos da organização e influenciam diretamente nos resultados dela.

\section{Conclusão}

A análise conjunta e simultânea das 85 variáveis escolhidas para representar uma organização empresarial mostrou o domínio das varáveis estratégicas sobre as demais, o que, de certa forma, era de se esperar. Do ponto de vista da estrutura e da dinâmica do sistema, as variáveis logísticas se situaram em um plano intermediário, próximas às variáveis de desempenho e superiores às características organizacionais. O fato de estarem próximas às variáveis de desempenho da organização mostram sua importância em relação a esse aspecto, ou seja, as variáveis logísticas estão diretamente associadas ao desempenho da organização como um todo.

As variáveis logísticas foram classificadas como dependentes, ou seja, elas não têm o papel de protagonistas. Elas dependem de uma determinação estratégica da organização para que possam ter efeito na dinâmica do sistema. Entretanto, na análise de correlação ficou claro o papel integrador das variáveis logísticas com as variáveis de estratégia e de desempenho. Isso mostra seu poder efetivo de ligar as decisões estratégicas aos resultados expressos pelas variáveis de desempenho.

\section{Referências}

AGAPIOU, A. et al. The role of logistics in the materials flow control process. Construction Management \& Economics, v. 16, n. 2, p. 131137, 1998.

AGUIAR, B.; CORREIA, W.; CAMPOS, F. Uso da Escala de Diferencial Semântico na Análise de Jogos. Salvador: Universidade Federal de Pernambuco, 2011. 
AKINTOYE, A.; MCINTOSH, G.; FITZGERALD, E. A Survey of Supply Chain Collaboration and Management in the UK Construction Industry. European Journal of Purchasing \& Supply Management, v. 6, n. 3, p. 159-168, 2000

ANTONIALLI, F. et al. Estratégia Organizacional: um estudo histórico e bibliométrico. Revista Espacios, v. 38, 2017.

ARORA, A.; ARORA, A. S.; SIVAKUMAR, K. Relationships Among Supply Chain Strategies, Organizational Performance, and Technological and Market Turbulences. The International Journal of Logistics Management, v. 27, n. 1, p. 206-232, 2016.

BALLOU, R.H. Logística Empresarial: transportes, administração de materiais e distribuição física. São Paulo: Atlas, 2011.

BALLOU, R. H. Gerenciamento da Cadeia de Suprimentos: logística empresarial. Bookman Editora, 2009.

BALLOU, R. H. The Evolution and Future of Logistics and Supply Chain Management. European business review, v. 19, n. 4, p. 332348, 2007.

BARBOSA, A. A. R.; MUNIZ, J.; SANTOS, A. U. Contribuição da Logística na Indústria da Construção Civil Brasileira. Revista Ciências Exatas, Taubaté, v. 2, n. 2, 2007.

BARNEY, J. Firm Resources and Sustained Competitive Advantage. Journal of Management, v. 17, n. 1, p. 99-120, 1991.

BOWERSOX, D. J.; CLOSS, D. J.; COOPER, M.

B. Gestão da Cadeia de Suprimentos e Logística. Rio de Janeiro: Elsevier, 2007.

EGAN, J. Rethinking Construction: report of the construction task force on the scope for improving the quality and efficiency of UK construction. London: Department of the Environment, Transport and the Regions, 1998.

FREITAS, H. et al. O Método de Pesquisa Survey. Revista de Administração, v. 35, n. 3, p. 105112, 2000.

GODET, M. De L'anticipation à L'action: manuel de prospective et de stratégie. Paris: Dunod, 1991.

GODET, M. MICMAC - Software de análise estrutural. Versão 5.3.0. [S. 1.], 21 dez. 2016. Disponível em: <http://laprospective.fr/methodsof-prospective/softwares/59-micmac.html>. Acesso em: 09 ago. 2019.
HAIR JUNIOR, J. et al. Fundamentos de Métodos de Pesquisa em Administração. Porto Alegre: Bookman, 2005.

HATEM, F. La Prospective: pratiques et méthodes. Paris: Economica, 1993.

LATHAM, M. Constructing the Team. Londres: HM Stationery Office, 1994.

LIN, C. et al. A Structural Equation Model of Supply Chain Quality Management and Organizational Performance. International Journal of Production Economics, v. 96, n. 3, p. 355-365, 2005.

LOVE, P. E. et al. A Model for Supporting InterOrganizational Relations in the Supply Chain. Engineering Construction and Architectural Management, v. 9, n. 1, p. 2-15, 2002.

MARTINHO, G. M. de S.; JESUS, M. E. da C. de; CAMPOS NETO, L. de S. Logística na Construção Civil: estudo de caso em uma construtora na região metropolitana de Belo Horizonte, MG. Revista Petra, v. 1, n. 1, 2015.

MINTZBERG, H. Criando Organizações Eficazes: estrutura em cinco configurações. São Paulo: Atlas, 2003.

MINTZBERG, H. Structure in Five Designing Effective Organizations. New York: Prentice Hall, 1983.

STONER, J. A. F.; FREEMAN, R. E.

Administração. 56. ed. Rio de Janeiro: LTC, 1999.

PALANDENG, I.-D. Influence Analysis of Supply Chain Management and Supply Chain Flexibility to Competitive Advantage and Impact on Company Performance of Fish Processing in Bitung City. Journal of Research in Business, Economics and Management, v. 10, n. 1, p. 1783-1802, 2018.

PAPADOPOULOS, G. et al. Supply Chain Improvement in Construction Industry. Universal Journal of Management, v. 4, n. 10, p. 528-534, 2016.

PFEFFER, J.; SALANCIK, G. R. The External Control of Organizations: a resource dependence perspective. Stanford: Stanford University Press, 1978.

PORTER, M. E. Vantagem Competitiva. Rio de Janeiro: Campus, 1993.

PORTER, M. E. Estratégia Competitiva. São Paulo: Elsevier Brasil, 2004. 
REZENDE, H. A.; JESUS, R. B. de; MOURA, R. C. A. A Logística no Contexto da Construção Cívil. Caderno de Graduação-Ciências Exatas e Tecnológicas, v. 1, n. 2, p. 135-146, 2013.

SAAD, M.; JONES, M.; JAMES, P. A Review of the Progress Towards the Adoption of Supply Chain Management (SCM) Relationships in Construction. European Journal of Purchasing \& Supply Management, v. 8, n. 3, p. 173-183, 2002.

SAMARTINI, A. L. S. Comparação Entre Métodos de Mensuração da Importância de Atributos em Produtos e Serviços. São Paulo, 2006.

SEPPÄNEN, O.; PELTOKORPI, A. A New Model for Construction Material Logistics: from local optimization of logistics towards global optimization of on-site production system. In: ANNUAL CONFERENCE OF THE INTERNATIONAL GROUP FOR LEAN CONSTRUCTION, 24., Boston, 2016.

Proceedings... Boston, 2016.
SKINNER, W. Manufacturing, the Formidable Competitive Weapon: the formidable competitive weapon. New York: John Wiley \& Sons, 1985.

SLACK, N.; CHAMBERS, S.; JOHNSTON, R. Administração da Produção. São Paulo: Atlas, 2009.

\section{SLACK, N. Vantagem Competitiva em}

Manufatura. São Paulo: Atlas, 2002.

VASCONCELLOS, E.; HEMSLEY, J. R.

Estrutura das Organizações. 4. ed. São Paulo: Cengage Learning, 2002.

VERMA, A.; SETH, N. A Conceptual Framework for Supply Chain Competitiveness. International Journal of Human and Social Sciences, v. 6, n. 1, p. 5-10, 2011.

VIDALAKIS, C.; TOOKEY, J. E.; SOMMERVILLE, J. The Logistics of Construction Supply Chains: the builders' merchant perspective. Engineering, Construction and Architectural Management, v. 18, n. 1, p. 66-81, 2011.

\section{Sofia Gauginski Maia}

Programa de Pós-Graduação em Engenharia Civil | Universidade Tecnológica Federal do Paraná | Rua Deputado Heitor Alencar Furtado, 5000, Cidade Industrial | Curitiba - PR - Brasil | CEP 81280-340 | Tel.: (41) 3279-4500 Ramal 4573 | E-mail: sofiaggmaia@gmail.com

\section{Alfredo larozinski Neto}

Departamento Acadêmico de Construção Civil | Universidade Tecnológica Federal do Paraná | E-mail: alfredo.iarozinski@gmail.com

\section{Sergio Edurado Gouvea da Costa}

Departamento de Engenharia de Produção | Pontifícia Universidade Católica do Paraná | Rua Imaculada Conceição, 1155 | Curitiba - PR Brasil | CEP 80215-901 | E-mail: s.gouvea@pucpr.br

\section{Cezar Augusto Romano}

Departamento Acadêmico de Construção Civil | Universidade Tecnológica Federal do Paraná | Tel.: (41) 3279-3115 | E-mail: romano.utfpr@gmail.com

\section{Revista Ambiente Construído}

Associação Nacional de Tecnologia do Ambiente Construído

Av. Osvaldo Aranha, 99 - 3o andar, Centro

Porto Alegre - RS - Brasil

CEP $90035-190$

Telefone: +55 (51) 3308-4084

Fax: +55 (51) 3308-4054

www. seer. ufrgs. br/ ambienteconstruido

E-mail: ambienteconstruido@ufrgs.br 